\title{
DISPONIBILIDADE DE Zn E Cu ADICIONADOS A SOLOS VIA LODO DE ESGOTO PARA PLANTAS DE ARROZ
}

\author{
ADRIANA MARLENE MORENO PIRES
}

Engenheira Agrônoma

Orientador: Prof ${ }^{\natural}$ Dra. MARIA EMÍlIA MATTIAZZO-PREZOTTO

Dissertação apresentada à Escola Superior de Agricultura "Luiz de Queiroz", Universidade de São Paulo, para obtenção do título de Mestre em Agronomia. Área de Concentração: Solos e Nutrição de Plantas.

PIRACICABA

Estado de São Paulo - Brasil

Dezembro - 1998 


\section{ERRATA}

Página 20, $3^{\circ}$ parágrafo - onde encontra-se Abreu et al. (1995) lê-se Abreu et al. (1996) Comparison of methods to evaluate heavy metals in organic wastes. Communications in Soil Science and Plant Analysis, v.27, p.1125-1135.

Página 25, $3^{\circ}$ parágrafo - onde encontra-se $\mathrm{Mg} \mathrm{kg}^{-1}$, lề-se $\mathrm{Mg} \mathrm{ha}^{-1}$.

Nas páginas 52 e 53, Apêndices 7 e 8, desconsiderar os valores encontrados para teores totais com o extrator Água Régia. 
Dados Internacionais de Catalogação na Publicação (CIP) DIVISĀO DE BIBLIOTECA E DOCUMENTAÇĀO - Campus "Luiz de Queiroz"/USP

Pires, Adriana Marlene Moreno

Disponibilidade de $\mathrm{Zn}$ e $\mathrm{Cu}$ adicionados a solos via lodo de esgoto para plantas de arroz / Adriana Marlene Moreno Pires. - - Piracicaba, 1998.

$55 \mathrm{p}$.

Dissertaçăo (mestrado) - E Escola Superior de Agricultura Luiz de Queiroz, 1998. Bibliografia.

1. Arroz 2. Cobre 3. Interação 4. Lodo de esgoto 5. Micronutriente 6. pH do solo 7. Relação solo-planta 8. Zinco I. Titulo 
Aos meus pais

\section{KLINGER e MARLENE,}

por todos momentos felizes em minha vida,

\section{DEDICO.}

\section{A DEUS,}

pela VIDA, humildemente

OFEREÇO. 


\section{AGRADECIMENTOS}

À Prof" Dra. Maria Emília Mattiazzo Prezotto, pela orientação e amizade.

Ao amigo "escravagista" Ronaldo Berton, (Boss) por sempre ter acreditado na minha capacidade.

A Tadeu Cavalcante Reis e Fábio Prata, meus novos "irmãozinhos", pela amizade sincera e apoio em todos momentos.

A Edmilson Renato Silva Ruiz (Di) por ter me mostrado que, apesar de tudo, compartilhar a vida com alguém vale a pena.

À Ana Rosa Martins dos Anjos pelo auxilio sempre que necessário e a todos colegas do curso de Solos e Nutrição de Plantas por todos momentos alegres que tivemos.

A todos professores e funcionários do Departamento de Química da ESALQ/USP, pelo apoio.

À Mônica Abreu, Jussara e Cleide Abreu do Instituto Agronômico de Campinas pela boa vontade com que sempre me atenderam.

A CAPES, pela concessão de bolsa no ano de 1997.

A FAPESP, pela concessão de bolsa no ano de 1998. 
Às secretárias Angélica e Geovana, pelo bom humor sempre que incomodadas.

À bibliotecária Eliana, pelas correções das Referências Bibliográficas.

À minha "irmãzinha" Katia Baldasso por saber compreender minha ausência durante este periodo, sempre me apoiando.

Ao meu irmão, Klinger Junior, que não me ajudou em nada, mas também não atrapalhou.

Finalmente, a todos aqueles que direta ou indiretamente colaboraram para realização deste trabalho. 


\section{SUMÁRIO}

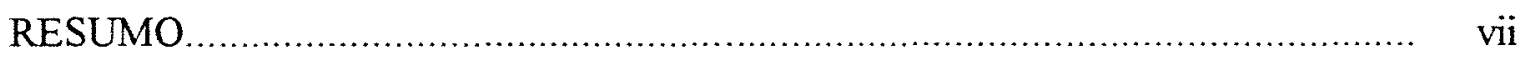

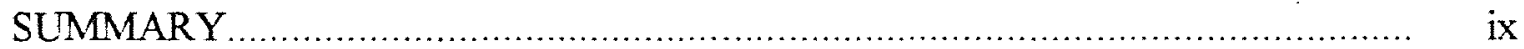

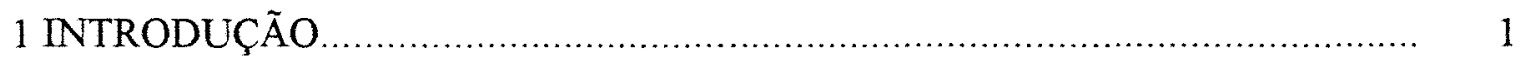

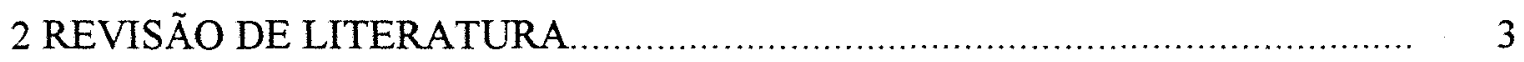

2.1 Zinco e cobre nas plantas......................................................................... 3

2.2 Comportamento de zinco e cobre nos solos ..................................................

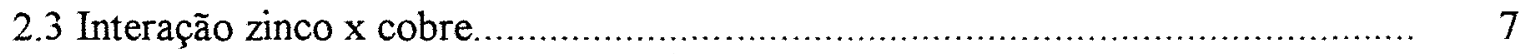

2.4 Extratores para avaliação da fitodisponibilidade de zinco e cobre........................ 8

2.5 Zinco e cobre no lodo de esgoto.................................................................. 8

3 MATERIAL E MÉTODOS..................................................................... 14

3.1 Localização da área experimental........................................................... 14

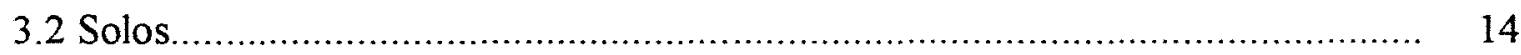

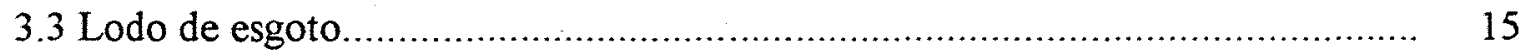

3.4 Sais de zinco e cobre........................................................................ 17

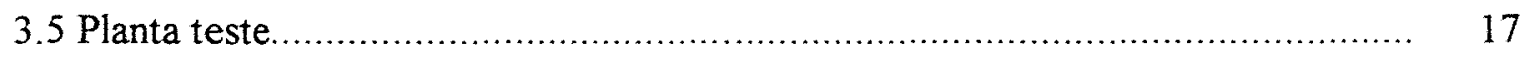

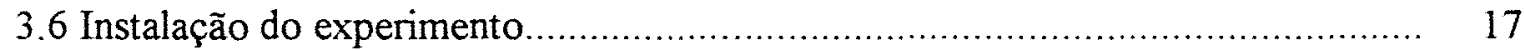

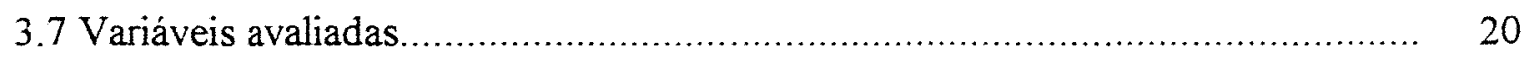

3.8 Tratamento estatístico dos dados obtidos ................................................... 21

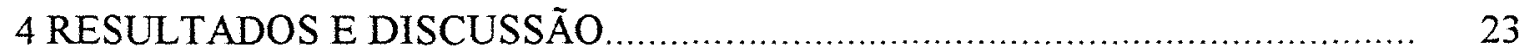

$4.1 \mathrm{pH}$ e condutividade elétrica dos solos...................................................... 23

4.2 Produção de massa seca da parte aérea e raiz................................................. 25

4.3 Fitodisponibilidade de zinco e cobre ........................................................ 27

4.4 Extratores químicos ....................................................................... 32

4.5 Interação entre zinco e cobre..................................................................... 33

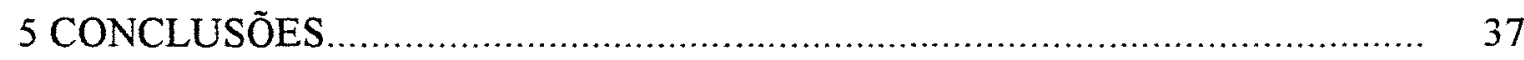


REFERÊNCIAS BIBLIOGRÁFICAS ................................................. 38

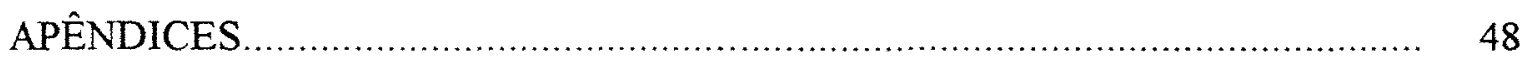




\title{
DISPONIBILIDADE DE Zn E Cu ADICIONADOS A SOLOS VIA LODO DE ESGOTO PARA PLANTAS DE ARROZ
}

\author{
Autora: ADRIANA MARLENE MORENO PIRES \\ Orientadora: Prof ${ }^{\mathfrak{e}}$ Dra. MARIA EMÍLIA MATTIAZZO-PREZOTTO
}

\section{RESUMO}

O comportamento de $\mathrm{Zn}$ e $\mathrm{Cu}$ aplicados a solos via lodo de esgoto em comparação com o fornecido por sais inorgânicos foi estudado num experimento em casa de vegetação, num esquema fatorial $2 \times 5$ para fontes e relações $\mathrm{Zn}: \mathrm{Cu}(5: 1,7: 1$, 1:1, 4:1 e testemunha sem adição de zinco e cobre), utilizando arroz (Oryza sativa) como planta teste. A avaliação da interação entre estes dois elementos também foi objetivo do estudo.

O experimento foi dividido em duas partes, cada uma utilizando um solo com características texturais distintas, a saber Latossolo Vermelho Escuro (LE-solo argiloso), e Latossolo Vermelho Amarelo ( $\mathrm{LV}$-solo arenoso). Os lodos, resultantes de diferentes épocas e processamentos, foram incorporados aos solos em quantidade correspondente a $50 \mathrm{Mg} \mathrm{ha}^{-1}$ (base seca). Os tratamentos cujas fontes de $\mathrm{Zn} \mathrm{e} \mathrm{Cu}$ foram sais inorgânicos, constituiram-se da adição de sulfato de zinco e sulfato de cobre em quantidades correspondentes às encontradas para as composições zinco e cobre nos lodos.

Foram avaliados os seguintes parâmetros: $\mathrm{pH}$, condutividade elétrica, teores totais de zinco e cobre do solo, fitodisponibilidade destes elementos analisada através de 
correlações estabelecidas entre as quantidades acumuladas por plantas de arroz e teores removidos dos solos pelos extratores $\mathrm{HCl} 0,1 \mathrm{~mol} \mathrm{~L}^{-1}$, Mehlich-3 e DTPA.

Os resultados obtidos permitiram as seguintes conclusões: a disponibilidade de zinco e cobre adicionados via lodo e sal foi diferente em função da fonte utilizada, nos dois solos. O sistema de tratamento gerador do lodo de esgoto influiu na disponibilidade de zinco e cobre adicionados ao solo via este resíduo. Para os dois solos tanto o DTPA, como o $\mathrm{HCl} 0,1 \mathrm{~mol} \mathrm{~L}^{-1}$ e o Mehlich-3 foram representativos da fitodisponibilidade de zinco e cobre. Não houve efeito significativo de zinco no solo sobre a absorção de cobre pela planta e vice versa. 


\title{
ZINC AND COPPER AVAILABILITY IN SEWAGE SLUDGE AND INORGANIC SALTS-AMENDED SOILS
}

\author{
Author: ADRIANA MARLENE MORENO PIRES \\ Adviser: Prof ${ }^{*}$ Dra. MARIA EMÍLIA MATTIAZZO-PREZOTTO
}

\section{SUMMARY}

The behaviour of zinc and copper in soils was studied in a pot experiment using sewage sludge and inorganic salts as sources of these elements. A fatorial $2 \times 5$ scheme was adpted for sources and $\mathrm{Zn}: \mathrm{Cu}$ relationships $(5: 1,7: 1,1: 1,4: 1$ and control treatement with neither $\mathrm{Zn}$ and $\mathrm{Cu}$ ). The test plant used was rice (Oryza sativa). The evaluation of the interaction among these two elements, was also observed in this study.

The experiment was divided in two parts, each one using a different textured soil, both classified as Hapludox. Sewage sludges resulting from different period and processing system were incorporated to soils in amount corresponding to $50 \mathrm{Mg} \mathrm{ha}^{-1}$ (dry weight basis). The treatments whose source was salt were constituted of the zinc and copper sulphate addition in amount corresponding to those added by the sludge.

The following parameters were evaluated: $\mathrm{pH}$, electric conductivity, total and soluble levels of these metals in soils. The availability of zinc and copper to rice was established by correlations among amounts accumulated by rice plants and those removed of the soils by the extractants $\mathrm{HCl} 0,1 \mathrm{~mol} \mathrm{~L}^{-1}$, Mehlich-3 and DTPA.

It was concluded that zinc and copper availability in both soils was different depending on the element's source. The amount of available zinc and copper for the rice plants was mainly dependent on soil $\mathrm{pH}$, as well as the sludge treatment system. 
Considering the extractor used for estimating bioavailability it was concluded that for both soils DTPA, $\mathrm{HCl} 0,1 \mathrm{~mol} \mathrm{~L}^{-1}$ and Mehlich-3 were representative. The results of the interaction Zinc x Copper have shown that one element didn't have influence in the absorption of the other one. 


\section{INTRODUÇÃO}

No Brasil, assim como em todo o mundo, os resíduos urbanos e industriais constituem uma grande preocupação devido às grandes quantidades geradas. Em nosso país, o descarte de resíduos líquidos "in natura" é geralmente feito pelo lançamento em cursos d'água. Residuos sólidos são usualmente depositados a céu aberto, em aterros sanitários ou industriais ou ainda incinerados. Qualquer uma destas alternativas resulta em degradação do ambiente.

Mesmo quando resíduos recebem tratamento tem-se a geração de outro resíduo, no caso particular do esgoto o resíduo é denominado lodo de esgoto ou biosólido. $\mathrm{O}$ descarte deste lodo consiste em um problema crescente nas grandes cidades, e as do Estado de São Paulo não fogem à regra. Sabe-se que a Estação de Tratamento de Esgoto de Barueri - São Paulo produz, em média, $164 \mathrm{Mg} \mathrm{dia}^{-1}$ de lodo. $\mathrm{O}$ mais interessante é que, sem um planejamento para o descarte desse lodo, ele se acumula no pátio da Estação. No final de 1992 existiam $110.000 \mathrm{Mg}$ de lodo no pátio da ETE-Barueri e estimava-se que no mês de abril de 1995 , estariam depositadas $240.000 \mathrm{Mg}$ do lodo, o que seria equivalente a 24 quadras, de $100 \times 100 \mathrm{~m}$, com $1 \mathrm{~m}$ de altura ${ }^{1}$.

Conforme Mattiazzo-Prezotto (1992) uma forma de minimizar o problema do descarte de lodo de esgoto seria seu uso agrícola, entretanto isso só deve ser feito depois de uma análise das características do resíduo e das consequências deste uso. Com isso, nutrientes e matéria orgânica seriam fornecidos aos solos, os altos custos que a disposição do lodo acarreta para os municipios seriam reduzidos, bem como os problemas de caráter ambiental seriam diminuídos.

Muitos estudos demonstram que o lodo de esgoto pode ser eficiente quando

\footnotetext{
'Comunicação pessoal realizada em visita à Estação de Tratamento de Esgoto de Barueri - SP.
} 
utilizado como fonte de nutrientes, no entanto pode-se ter problemas com poluição do solo por metais pesados. A concentração máxima permissivel desses elementos presentes em resíduos destinados ao uso agrícola é objeto de estudo do órgão responsável pelo controle de poluição no Estado de São Paulo (CETESB).

Um agravante no uso agricola do lodo de esgoto está no fato de que os nutrientes não estão em concentrações adequadas ao balanço nutricional da planta. No caso de cobre e zinco a relação apresentada por plantas e solos é de aproximadamente $5 \mathrm{Zn}: 1 \mathrm{Cu}$ (cálculo baseado nos teores médios citados por Kiekens, 1990 e Baker, 1990) e no lodo esta relação é bastante variável em função da sua origem. Portanto, é interessante determinar as interações entre estes elementos presentes em diferentes concentrações e verificar se estas interferem na absorção dos mesmos pela planta. Existem poucos trabalhos em que apenas estes elementos são os fatores avaliados. $\mathrm{O}$ número de publicações é ainda menor para as condições de clima e solo tropicais.

Outro aspecto importante é o de que muitos trabalhos que vistam a definição das quantidades permissiveis de metais pesados a serem adicionados ao solo via resíduos são realizados por meio de experimentos em que a fonte dos metais são sais inorgânicos, sugerindo que a disponibilidade dos metais via sal ou algum resíduo orgânico seria a mesma.

Neste contexto, sendo zinco e cobre metais pesados e micronutrientes, o presente trabalho teve como objetivo avaliar a disponibilidade de $\mathrm{Zn}$ e $\mathrm{Cu}$ aplicados a solos sob forma de lodo de esgoto em comparação com o fornecido por sais inorgânicos, utilizando arroz como planta teste. A avaliação da interação entre estes dois elementos também foi objetivo do estudo. 


\section{REVISĀO DE LITERATURA}

\subsection{Zinco e Cobre nas plantas}

Zinco e cobre são micronutrientes, cuja falta causa sérios distúrbios ao metabolismo vegetal, diminuindo a produtividade agricola, sendo que vários trabalhos, entre eles o de Lèon et al. (1985) tem relatado decréscimo de produção em culturas onde a deficiência de zinco e cobre foi constatada.

Ritchey et al. (1986) citaram que a deficiência de zinco, em comparação com a dos outros micronutrientes, é o fator que mais tem limitado a produção de arroz de sequeiro no Brasil.

Segundo Dechen et al. (1991) os teores de zinco na planta são variáveis, em função da espécie e do tipo de solo em questão. Com frequência encontram-se teores compreendidos no intervalo de 20 a $50 \mathrm{mg} \mathrm{kg}^{-1}$, sendo comum o aparecimento de sintomas de deficiência quando a concentração nas plantas está abaixo de $20 \mathrm{mg} \mathrm{kg}^{-1}$. A aproximação de uma classificação para os teores de zinco nas folhas que atingiram a maturidade é a seguinte (Kiekens, 1990):

- Deficiente $=<10-20 \mathrm{mg} \mathrm{kg}^{-1}$ de $\mathrm{Zn}$ na matéria seca;

- Suficiente ou Normal $=25$ a $150 \mathrm{mg} \mathrm{kg}^{-1}$ de $\mathrm{Zn}$ na matéria seca;

- Excessivo ou Tóxico $=>400 \mathrm{mg} \mathrm{kg}^{-1}$ de $\mathrm{Zn}$ na matéria seca.

Baker (1990) citou que a concentração nas plantas compreende o intervalo de 5 a $20 \mathrm{mg} \mathrm{kg}^{-1}$ de $\mathrm{Cu}$ na matéria seca, podendo ocorrer variações em que os teores atingem os extremos de 1 a $30 \mathrm{mg} \mathrm{kg}^{-1}$ de $\mathrm{Cu}$. A determinação de valores padrões para os teores 
de cobre associados com sintomas de deficiência e toxidez é dificultada pelas variações que ocorrem conforme estuda-se diferentes espécies de plantas e tipos de solo.

Um aspecto importante a ser destacado é que zinco e cobre, além de micronutrientes são também metais pesados. Nesta classificação considera-se como metais pesados aqueles com densidade atômica maior que $6 \mathrm{~g} \mathrm{~cm}^{-3}$ (Alloway, 1990), e dessa forma o acúmulo de $\mathrm{Zn}$ e $\mathrm{Cu}$ no solo é importante quando se considera o uso agricola de residuos que contenham estes elementos.

\subsection{Comportamento de Zinco e Cobre nos solos}

Para avaliar o impacto ambiental provocado pelos metais pesados adicionados aos solos é importante o conhecimento dos processos que governam a disponibilidade destes elementos para as plantas (Sposito et al., 1982).

A fitodisponibilidade dos metais pesados depende da especiação dos mesmos no solo (Chukwuma, 1995). As características do solo onde o metal está presente constituem um fator essencial no. estudo do comportamento de zinco e cobre. Por exemplo: em solos ricos em matéria orgânica, ácidos húmicos e ácidos fúlvicos tendem a formar complexos com íons de metais pesados e mantê-los em solução (Sposito et al., 1979); em solos com óxidos de ferro e alumínio os metais tendem a estar coprecipitados juntos a estes óxidos (Fagbami et al., 1985).

As características inerentes ao metal influem diretamente na especiação do mesmo no solo. Conforme Raij (1991) o cobre tende a formar ligações covalentes em seus compostos. Quando em solução o cobre pode aparecer como $\mathrm{Cu}^{+}$e $\mathrm{Cu}^{2+}$. Entretanto em soluções aquosas a forma monovalente só ocorre em concentrações extremamente baixas. Também é citada a presença de cobre complexado por ions inorgânicos ou na matéria orgânica. Em soluções com pH alcalino, o íon tende a formar hidróxidos.

Vários autores citam a grande estabilidade dos complexos de cobre com os ligantes orgânicos resultando em uma baixa ocorrência como íon livre na solução. Dessa 
forma a matéria orgânica desempenha papel fundamental no comportamento deste elemento no solo (Colleman, 1956; Holtzclaw et al., 1978; Chino et al., 1992; Kreij et al., 1993; Rodella, 1993 e Mattiazzo-Prezotto, 1994).

Kabata-Pendias \& Pendias (1985) relatam que a disponibilidade de cobre é controlada principalmente pelas reações deste elemento com sítios de troca da fase sólida, incluindo tanto os inorgânicos como orgânicos. $\mathrm{O}$ pH é citado como um fator importante na fitodisponibilidade de cobre, de maneira que quanto mais ácido o meio, maior a quantidade de cobre disponivel (Alloway, 1991; Smith, 1994; Oliveira, 1995).

O zinco, por sua vez, é bastante eletropositivo, sendo que sua forma mais comum em solução é a do cátion $\mathrm{Zn}^{2+}$. Entretanto esse cátion pode ocorrer formando complexos com ligantes orgânicos e inorgânicos (Raij, 1991).

Os minerais de argila e o pH do solo são mais importantes no controle da solubilidade de zinco em relação à complexação orgânica e a precipitação como carbonatos e sulfatos (Kabata-Pendias \& Pendias, 1985).

Outro fator que influi na disponibilidade destes metais pesados é a presença no solo de grandes quantidades de cálcio, provavelmente pela competição por sítios ativos (Cavallaro \& McBride, 1978).

Reddy et al. (1995) ao avaliarem a solubilidade e mobilidade de $\mathrm{Zn}, \mathrm{Cu}$ e $\mathrm{Pb}$ em amostras de solos de Wyoming - E.U.A. observaram que em $\mathrm{pH}$ próximo a neutralidade aqueles elementos se encontravam presentes na solução do solo predominantemente na forma de complexos com carbono orgânico dissolvido. Apenas em valores de $\mathrm{pH}$ próximos de 2,4 ocorreram maiores concentrações das formas iônicas livres $\mathrm{Cu}^{2+}$ e $\mathrm{Zn}^{2+}$.

Muitos trabalhos como o de Lepp et al. (1984), onde foi estudada a contaminação do solo por residuos de fungicidas, citam a baixa disponibilidade de cobre para as plantas. Lidon \& Henriques (1990) citam que esta redução na mobilidade provocou uma diminuição no aparecimento de sintomas de toxicidade do elemento em plantas de arroz cultivadas em solos ricos em matéria orgânica.

Castillo et al. (1980) observaram que embora exista uma relação significativa entre a máxima adsorção de $\mathrm{Cu}$ e a quantidade de matéria orgânica no solo, esta relação 
não foi encontrada para zinco. Os autores avaliaram 49 tipos diferentes de solo e verificaram que em todos os casos a adsorção de cobre foi maior do que a de zinco.

Shuman (1988) estudou a distribuição de zinco nas várias frações de solos ácidos ( $\mathrm{pH}$ entre 4,5 e 6,2), com CTC entre 3 e 13 emg $100 \mathrm{~g}^{-1}$, tratados com palha de trigo e metais sob forma de sais. Os resultados demonstraram que o zinco predominava na forma inorgânica coprecipitando junto a óxidos de ferro e aluminio formados quando ocorria elevação do pH pela adição de material orgânico.

Mattiazzo-Prezotto (1994) estudou o comportamento de vários metais pesados em solos tropicais (Areia Quartzoza, Podzólico Vermelho Amarelo, Terra Roxa Estruturada e Latossolo Vermelho Escuro). Para zinco o autor cita que este encontra-se predominantemente na forma inorgânica e catiônica. $\mathrm{Na}$ faixa de $\mathrm{pH}$ entre 4,0 e 4,4 a retenção deste metal no solo é baixa, devido à competição com os íons $\mathrm{H}^{+}$pelos sítios de adsorção do solo. Com o aumento do $\mathrm{pH}$, a retenção é incrementada, sendo que a partir de $\mathrm{pH} 5,5$ apenas parte da quantidade retida consegue ser extraída por $\mathrm{HCl} 0,1 \mathrm{~mol} \mathrm{~L}^{-1}$. Quanto ao cobre, os resultados indicaram que este metal ocorre principalmente associado a materiais orgânicos que apresentam baixa mobilidade. Indicação disso foi que os menores teores de $\mathrm{Cu}$ livre foram determinados nos solos com maiores teores de matéria orgânica.

Bertoncini (1997) avaliando a lixiviação de metais pesados em solos tratados com lodo de esgoto, observou que a maior fração de cobre lixiviada ocorreu em uma areia quartzoza, onde também foram observadas as maiores perdas de C-orgânico solúvel em água, refletindo a ligação do cobre a ligantes orgânicos solúveis.

Ladonin \& Margolina (1997) num estudo das interações entre os metais pesados e ácidos húmicos do solo citaram que a competição entre $\mathrm{Cd}, \mathrm{Cu}$ e $\mathrm{Zn}$ por sítios ativos da superficie de ácidos húmicos ocorre quando a concentração destes ácidos no solo é menor que $1,25 \mathrm{~g} \mathrm{~L}^{-1}$, apresentando a seguinte ordem de preferência de adsorção: $\mathrm{Cu}>$ $\mathrm{Zn}>\mathrm{Cd}$. 


\subsection{Interação Zinco $x$ Cobre}

A literatura sobre interação entre zinco e cobre não é conclusiva. Alguns autores como Chaudry \& Loneragan (1970); Jalali \& Takkar (1979) e Moussa et al. (1996) citam que existe uma relação antagônica entre os dois elementos no que diz respeito à absorção dos mesmos pelas plantas; outros como Brar \& Sekhon (1978) não encontraram nenhum efeito na absorção pelas plantas de um sobre o outro; ainda existem aqueles como Butley \& Bray (1956) e Chew et al. (1979) que constataram aumento da absorção pelas plantas de um elemento quando na presença do outro.

Uma explicação para esta contradição nos resultados foi a dada por Arora \& Sekhon (1982), que afirmam que o comportamento destes metais varia consideravelmente conforme a natureza dos solos, a quantidade de metais presentes e/ou adicionadas aos mesmos e a cobertura vegetal destes solos. Neste mesmo trabalho, em que é avaliada a interação entre zinco e cobre em 11 solos diferentes, sob cultivo com trigo, os autores relatam a ocorrência de interação antagônica sempre que um dos elementos haviam sido aplicados em baixa concentração em relação ao outro e que estes efeitos adversos que ocorreram não puderam ser revertidos por altas concentrações do outro.

Barbosa Filho et al. (1990) obtiveram um aumento significativo na produção de grãos de arroz em um Latossolo Vermelho Escuro ao adicionar zinco $(0,1,2,6$ e $18 \mathrm{mg}$ $\left.\mathrm{kg}^{-1}\right)$ e cobre $\left(0 ; 1,5\right.$ e 4,5 $\left.\mathrm{mg} \mathrm{kg}^{-1}\right)$, sugerindo uma interação positiva. A adição unicamente de cobre não provocou um aumento significativo na produção.

Mesquita et al. (1996) avaliaram a interação entre zinco e cobre em um solo calcário. Os resultados obtidos demonstraram que uma quantidade maior de $\mathrm{Cu}$ foi adsorvida em relação ao $\mathrm{Zn}$ quando os teores de $\mathrm{Cu}$ e $\mathrm{Zn}$ na forma trocável eram baixos. A adsorção de zinco foi proporcionalmente mais afetada por $\mathrm{Cu}$ do que o contrário. 
2.4 Extratores para a avaliação da fitodisponibilidade de $\mathrm{Zn}$ e Cu

Em todo mundo vários estudos tem sido desenvolvidos com o objetivo de determinar as soluções extratoras mais adequadas para avaliação da fitodisponibilidade dos metais pesados (Singh \& Norwal, 1984; Haddad \& Evans, 1993). No Brasil, estudos sobre métodos de análise de solo para metais potencialmente tóxicos são poucos e não existem procedimentos definidos pela pesquisa (Abreu et al., 1995). Bertoncini (1997) cita que a escolha da solução extratora deve ser feita em função da cultura, tipo de solo e das características do metal avaliado.

Neste contexto, observa-se que existem diversos tipos de soluções extratoras. Alguns pesquisadores utilizam soluções de sais neutros, tais como $\mathrm{CaCl}_{2}$ 0,05 e $0,01 \mathrm{~mol}$ $\mathrm{L}^{-1}$, para determinar as frações trocáveis de metais. Também em estudos de fitodisponibilidade são muito utilizados os extratores ácidos, principalmente Mehlich-1, Mehlich-3, $\mathrm{HCl} 0,05$ e $0,1 \mathrm{~mol} \mathrm{~L}^{-1}$, que extraem quantidades próximas ao total. Outros extratores são os ligantes orgânicos, como o DTPA e o EDTA, que extraem preferencialmente metais ligados aos carbonatos e a compostos orgânicos (Sposito et al., 1982; Keller \& Vedy, 1994; McGrath \& Cegarra, 1992).

Entre as soluções extratoras, algumas tem sido constantemente utilizadas nas

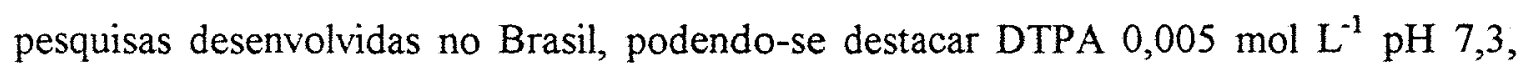
Mehlich-3 e $\mathrm{HCl}$ 0,1 mol L ${ }^{-1}$ (Oliveira, 1995; Bertoncini, 1997).

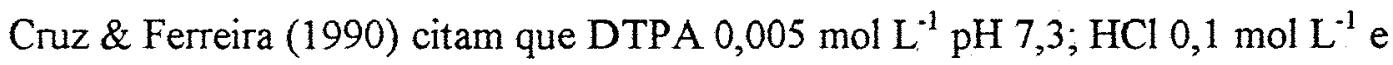
$\mathrm{Na}_{2}$ EDTA 1,0\% são os extratores indicados para a avaliação de cobre disponível no solo, levando-se em consideração a correlação com teores absorvidos pela planta, coeficiente de variação e praticidade do método.

\subsection{Zinco e Cobre em Lodo de Esgoto}

Uma definição simples e geral que pode ser dada para lodo de esgoto é a de que 
este consiste em um material predominantemente orgânico originário do tratamento de águas residuais provenientes de centros urbanos e/ou industriais. A origem do esgoto e os processos utilizados para o seu tratamento são alguns dos responsáveis por variações na composição e concentrações dos elementos químicos do lodo.

O lodo de esgoto é rico em matéria orgânica, que pode melhorar as propriedades químicas e fisicas do solo, sendo as últimas beneficiadas pela melhor agregação, influindo na infiltração de água e aeração no solo. Sob este aspecto Díaz-Burgos \& Polo (1991) concluíram que a incorporação de lodo de esgoto tem sido uma atividade cada vez mais utilizada devido à adição de matéria orgânica. Melo et al. (1994) citaram que em solos de clima tropical e subtropical, onde a matéria orgânica desempenha um papel de fundamental importância na CTC, a utilização agrícola do lodo de esgoto tem um atrativo ainda maior.

Além da matéria orgânica, o lodo contém $\mathrm{N}$ e $\mathrm{P}$ em concentrações que poderiam suprir a necessidade destes nutrientes para as plantas, sendo porém deficiente em potássio. Muitos trabalhos como os de Bunting (1963) e Oliveira et al. (1995) citam esta deficiência.

Resumindo as características positivas do uso agrícola do lodo tem-se a seguinte afirmação de Costa et al. (1991): a adição da fração orgânica proveniente de esgoto ao solo tem potencial de incrementar a fertilidade deste solo agindo diretamente sobre suas propriedades biológicas e químicas; que por sua vez, ativam a população microbiana, a capacidade de retenção de água e nutrientes, melhoram a estrutura do solo, entre muitas outras.

Um problema a ser ressaltado é o de que o uso do lodo de esgoto pode ser limitado pela presença de patógenos, sais solúveis, metais pesados e compostos orgânicos persistentes, segundo Sommers \& Giordano (1984). A concentração de alguns metais pesados presentes em lodos podem ser observadas na Tabela 1. 
Tabela 1. Concentração de metais pesados em lodo de esgoto (base seca)

\begin{tabular}{|c|c|c|c|}
\hline Elemento & Mínimo & Máximo & Mediana \\
\hline & -- & $-\mathrm{mg} \mathrm{kg}^{-1}$ & 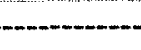 \\
\hline Arsênio & 1,1 & 230 & 10 \\
\hline Cádmio & 1 & 3410 & 10 \\
\hline Crômio & 10 & 99000 & 500 \\
\hline Cobre & 84 & 17000 & 800 \\
\hline Chumbo & 13 & 26000 & 500 \\
\hline Mercúrio & 0,6 & 56 & 6 \\
\hline Molibdênio & 0,1 & 214 & 4 \\
\hline Níquel & 2 & 5300 & 80 \\
\hline Selênio & 1,7 & 17,2 & 5 \\
\hline Zinco & 101 & 49000 & 1700 \\
\hline
\end{tabular}

Fonte: Logan \& Chaney (1983)

Devido a amplitude de variação nos teores de metais pesados presentes no lodo de esgoto observada na Tabela 1, ela pode ser considerada representativa para lodos obtidos nas estações de tratamento de esgoto do Estado de São Paulo, haja visto as características de metais presentes em lodos que aparecem em Barretto (1995), Oliveira (1995), Bertoncini (1997).

Muitos trabalhos estudam as consequências da presença de grandes quantidades de metais pesados no lodo de esgoto, entre eles os de Logan \& Chaney (1983) e Alloway (1990). Embora muitos desses metais sejam considerados micronutrientes, quando absorvidos em concentrações elevadas podem provocar toxicidade, colocando em risco as plantas, bem como a saúde humana e/ou animal. Entre esses micronutrientes podem-se citar o $\mathrm{Zn}$ e $\mathrm{Cu}$.

Conforme Berton et al. (1989) aplicações de 0, 40 e $80 \mathrm{Mg}$ ha $^{-1}$ de lodo em base seca (proveniente da Estação de Tratamento da Vila Leopoldina, São Paulo-SP) em cinco solos representativos do Estado de São Paulo (Terra Roxa Estruturada, Podzólico 
Vermelho Amarelo, Latossolo Vermelho Amarelo, Latossolo Roxo e Latossolo Vermelho Escuro). Concluiu-se que com o aumento da dose, também foi aumentada a concentração de zinco e cobre no solo e, consequentemente a absorção destes elementos pelas plantas de milho, sem que fossem observadas diminuições na produção de matéria seca.

Pedreño et al. (1996) observaram um incremento na concentração de $\mathrm{Fe}, \mathrm{Cu}$ e $\mathrm{Zn}$ no solo quando adicionou-se $10 \mathrm{Mg} \mathrm{ha}^{-1}$ de lodo (base seca), além de um incremento na produtividade de tomates cultivados sob este solo.

O monitoramento de solos tratados com lodo deve ser uma constante para evitar problemas de toxicidade de metais. A aplicação de lodos de esgoto a solos agricolas é regulada por lei nos Estados Unidos. As quantidades máximas de metais pesados que podem ser adicionadas ao solo podem ser observadas na Tabela 2. Além dos Estados Unidos, na Europa a utilização do lodo como fertilizante também é bem difundida. Vários países, como Holanda, França e Suécia, apresentam suas próprias regulamentações no que diz respeito aos metais pesados, sendo muitas vezes leis mais rígidas do que a EPA. No Estado de São Paulo os limites adotados pela legislação americana estão sendo utilizados pelo órgão responsável pelo controle da poluição no que se refere ao uso agrícola de lodos (CETESB).

Apesar da concentração de zinco e cobre no lodo de esgoto ser bastante variável, os teores apresentados na Tabela 1, indicam que a relação entre as concentrações de zinco e cobre em lodo seria de aproximadamente 2:1. Se forem analisadas as concentrações de $\mathrm{Zn}$ e $\mathrm{Cu}$ encontradas nas plantas pode-se notar que a relação está por volta de 5: 1 (cálculo baseado nos teores médios citados por Kiekens, 1990 e Baker, 1990). Portanto, quando o lodo for utilizado, pode ocorrer um desbalanço nutricional na planta, afetando negativamente seu desenvolvimento. 
Tabela 2. Quantidades máximas de metais pesados permitidas no lodo de esgoto (base seca) e taxa máxima de aplicação anual e acumulada no solo agrícola de acordo com a legislação 40 CFR (EPA), parte 503, regulamentadora do uso de lodo de esgoto nos EUA, vigente a partir de 1993.

\begin{tabular}{lccc}
\hline Elemento & $\begin{array}{l}\text { Quantidade máxima no lodo } \\
\text { anual }\end{array}$ & $\begin{array}{c}\text { Taxa máxima de aplicação } \\
\mathrm{mg} \mathrm{kg}^{-1}\end{array}$ & $\begin{array}{c}\text { Taxa máxima de aplicação } \\
\text { acumulada }\end{array}$ \\
\hline Arsênio & 75 & 2 & $\mathrm{~kg} \mathrm{ha}^{-1} \mathrm{ano}^{-1}$ \\
Cádmio & 85 & 1,9 & 41 \\
Crômio & 3000 & 150 & 39 \\
Cobre & 4300 & 75 & 3000 \\
Chumbo & 840 & 15 & 1500 \\
Mercúrio & 57 & 0,85 & 300 \\
Molibdênio & 75 & 0,90 & 17 \\
Niquel & 420 & 21 & 18 \\
Selênio & 100 & 5 & 420 \\
Zinco & 7500 & $\mathbf{1 4 0}$ & 100 \\
& & & $\mathbf{2 8 0 0}$ \\
\hline
\end{tabular}

Fonte: U. S. Environmental Protection Agency (1993) - EPA

Wallace \& Wallace (1994), analisando as concentrações de $\mathrm{Zn}$ e Cu presentes nos solos de áreas destinadas a paisagismo tratadas há mais de 40 anos com lodo de esgoto, verificaram que sintomas de toxicidade se manifestaram sempre que os teores de $\mathrm{Zn} \mathrm{e} \mathrm{Cu}$ removidos por DTPA $0,005 \mathrm{~mol} \mathrm{~L}^{-1}$ excediam 80 e $20 \mathrm{mg} \mathrm{kg}^{-1}$ respectivamente. Os autores sugeriram que mais atenção deva ser dada ao aumento da concentração daqueles metais no solo, provocada pelo uso contínuo de lodo de esgoto.

Arteaga (1996) realizou um estudo com doses de lodo proveniente da Siderúrgica Mendes Junior de Juiz de Fora - MG contendo metais pesados adicionadas a um Latossolo Roxo com presença ou ausência de corretivo de acidez e o tempo de incubação do lodo com o solo antes do plantio de trigo. Observou-se que a concentração de $\mathrm{Cu}$ 
fortemente ligado à matéria orgânica decresceu com as doses adicionadas $(0,50,100 \mathrm{e}$ $150 \mathrm{mg} \mathrm{dm}^{-3}$ de cobre e $0,15,20$ e $45 \mathrm{mg} \mathrm{dm}^{-3}$ de zinco) no solo com e sem calagem. $O$ teor de $\mathrm{Cu}$ nas plantas aumentou com a calagem, o que não ocorreu com o zinco. Os teores de zinco nas frações solúvel e trocável, diminuiram na presença de calagem. $O$ autor concluiu que existe uma reduzida participação da matéria orgânica do lodo na dinâmica de $\mathrm{Zn}$ no solo. A concentração maior de zinco foi observada na raiz, seguida de parte aérea e grãos de trigo. O cobre também obedeceu a mesma ordem de concentração nas diferentes partes da planta.

Os elementos químicos zinco e cobre são metais pesados, sendo objeto de preocupação quando se utiliza o lodo de esgoto na agricultura. Além disso, estes elementos são também micronutrientes, sendo muito estreita a distância entre o teor benéfico e o prejudicial. Portanto, é muito importante que trabalhos que avaliem o risco da ocorrência de deficiência e toxidez de zinco e cobre em plantas cultivadas sob solos em que lodo de esgoto é adicionado sejam realizados. 


\section{MATERIAL E MÉTODOS}

\subsection{Localização da área experimental}

O presente trabalho foi realizado em condições de casa-de-vegetação, junto ao Departamento de Química / Setor de Química Ambiental da Escola Superior de Agricultura "Luiz de Queiroz", ESALQ/USP em Piracicaba-SP.

\subsection{Solos}

O experimento foi dividido em duas partes, cada uma com um tipo de solo. A principal diferença entre os solos foi a textura. Um deles, classificado como Latossolo Vermelho Escuro (LE-solo argiloso), foi obtido na Estação Experimental do Instituto Agronômico de Campinas, localizada em Piracicaba. O segundo solo, classificado como Latossolo Vermelho Amarelo (LV-solo arenoso), foi coletado na própria ESALQ. Amostras de terra de ambos solos foram retiradas da camada superficial $(0-30 \mathrm{~cm})$, secas ao ar, peneiradas (malha de $2 \mathrm{~mm}$ ) e homogeneizadas. Em seguida, foram submetidas às análises para caracterização química (Tabela 3), granulometria e teores totais de óxidos de silício, ferro e aluminio (Tabela 4). 
Tabela 3. Caracterização química dos solos*.

\begin{tabular}{|c|c|c|c|c|c|c|c|c|c|c|c|}
\hline Solos & $\mathrm{pH}$ & M.O. & $\mathrm{P}$ & $\mathrm{K}$ & $\mathrm{Ca}$ & $\mathrm{Mg}$ & $\mathrm{H}+\mathrm{Al}$ & Al & SB & CTC & $\mathrm{V}$ \\
\hline & $\left(\mathrm{CaCl}_{2}\right)$ & $\mathrm{g} \mathrm{dm}^{-3}$ & $\mathrm{mg} \mathrm{dm^{-3 }}$ & $\ldots$ & $\ldots$ & - & $\mathrm{mol}_{\mathrm{c}} \mathrm{dm}$ & & & 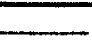 & $\%$ \\
\hline LV & 4,7 & 29 & 6 & 1,0 & 14 & 7 & 31 & 0 & 22 & 53 & 42 \\
\hline LE & 4,3 & 26 & 12 & 2,7 & 13 & 9 & 52 & 4 & 25 & 77 & 32 \\
\hline
\end{tabular}

* Análise segundo Raij \& Quaggio (1983).

Tabela 4. Granulometria e teores totais de óxidos de silício, ferro e alumínio dos solos*.

\begin{tabular}{lrrrrrrr}
\hline Solos & argila & areia grossa & areia fina & silte & $\mathrm{SiO}_{2}$ & $\mathrm{Fe}_{2} \mathrm{O}_{3}$ & $\mathrm{Al}_{2} \mathrm{O}_{3}$ \\
\hline & 24,9 & 21,1 & 47,7 & 6,3 & 7,80 & 3,01 & 6,80 \\
$\mathrm{LV}$ & 50,0 & 9,3 & 21,5 & 19,2 & 17,00 & 12,58 & 13,20 \\
$\mathrm{LE}$ & 50,0 & & &
\end{tabular}

\subsection{Lodo de Esgoto}

A fim de se obter lodos com diferentes proporções entre $\mathrm{Zn}$ e $\mathrm{Cu}$, foram feitas análises de lodos coletados em várias épocas e que sofreram tratamentos distintos. Desta forma, foram escolhidos lodos provenientes da Estação de Tratamento de Esgotos (ETE) de Barueri - SABESP, Barueri - SP, resultantes do processo de tratamento de digestão anaeróbica.

Nesta estação, uma etapa importante do tratamento no que diz respeito à utilização agrícola do lodo é o tratamento químico em que é adicionado cloreto férrico e cal a este resíduo, elevando seu $\mathrm{pH}$ a valores compreendidos entre 9 e 13. Pretende-se com esta etapa aumentar a eficiência da prensagem, diminuindo a umidade que normalmente é bastante elevada.

Em um dos lodos (lodo 4:1), a adição de cal e cloreto férrico foi substituída pela adição de polímeros sintéticos, de maneira que o valor de $\mathrm{pH}$ apresentado por este lodo é 
inferior aos valores determinados nos outros. Sabe-se que problemas de salinização ocorrem frequentemente quando adiciona-se lodo de esgoto ao solo. Espera-se que para este lodo, estes problemas sejam amenizados, devido ao fato deste resíduo ter menor alcalinidade.

As coletas foram feitas em diferentes épocas, a saber: Lodo 5:1: julho /1997; Lodo 7:1: novembro /1997, Lodo 1:1: janeiro /1998; Lodo 4:1: outubro /1997.

A composição química dos lodos, determinada no Laboratório de Química Ambiental do Departamento de Química da ESALQ/USP, são apresentadas na Tabela 5.

Tabela 5. Características químicas dos lodos de esgoto utilizados. Resultados expressos no material seco à $65^{\circ} \mathrm{C}$.

\begin{tabular}{|c|c|c|c|c|}
\hline Características & Lado 5:1 & Lodo $7: 1$ & Lodo 1:1 & Lodo 4:1 \\
\hline Umidade $\left(\mathrm{g} \mathrm{kg}^{-1}\right)$ & 595 & 587 & 592 & 408 \\
\hline $\left.\mathrm{pH}\left(\mathrm{CaCl}_{2} 0,01 \mathrm{~mol} \mathrm{~L}^{-1}\right)\right)$ & 9,8 & 8,6 & 8,1 & 6,3 \\
\hline C- oxidável $\left(\mathrm{g} \mathrm{kg}^{-1}\right)$ & 195 & 191 & 183 & 154 \\
\hline Matéria Orgânica $\left(\mathrm{g} \mathrm{kg}^{-1}\right)$ & 315 & 302 & 294 & 213 \\
\hline Relação $\mathrm{C} / \mathrm{N}$ & 10 & 10 & 10 & 5 \\
\hline N-total $\left(\mathrm{g} \mathrm{kg}^{-1}\right)$ & 19 & 19 & 18 & 32 \\
\hline P-total $\left(\mathrm{g} \mathrm{kg}^{-1}\right)$ & 11 & 10 & 9 & 21 \\
\hline K-total $\left(\mathrm{g} \mathrm{kg}^{-1}\right)$ & 1,11 & 1,10 & 1,15 & 1,37 \\
\hline Ca-total $\left(\mathrm{g} \mathrm{kg}^{-1}\right)$ & 132 & 139 & 144 & 24 \\
\hline Mg-total $\left(\mathrm{g} \mathrm{kg}^{-1}\right)$ & 4,0 & 4,0 & 3,8 & 3,3 \\
\hline Na-total $\left(\mathrm{g} \mathrm{kg}^{-1}\right)$ & 0,61 & 0,58 & 0,64 & 0,69 \\
\hline Fe-total $\left(\mathrm{g} \mathrm{kg}^{-1}\right)$ & 48 & 47 & 45 & 54 \\
\hline Cd-total (mg kg-1) & 15 & 13 & 14 & 17 \\
\hline Cr-total ( $\left.\mathrm{mg} \mathrm{kg}^{-1}\right)$ & 361 & 347 & 324 & 609 \\
\hline Mn-total (mg kg-1) & 239 & 234 & 233 & 329 \\
\hline Ni-total $\left(\mathrm{mg} \mathrm{kg}^{-1}\right)$ & 199 & 201 & 199 & 408 \\
\hline $\mathrm{Zn}$-total (mg kg-1) & 2048 & 5472 & 2087 & 3488 \\
\hline Cu-total (mg kg-1) & 414 & 770 & 2460 & 878 \\
\hline Relação Zn : Cu & $5: 1$ & $7: 1$ & $1: 1$ & $4: 1$ \\
\hline
\end{tabular}


O estudo comparativo foi feito utilizando soluções com os sais: Sulfato de zinco $\left(\mathrm{ZnSO}_{4} .7 \mathrm{H}_{2} \mathrm{O}\right)$ e Sulfato de cobre $\left(\mathrm{CuSO}_{4} .5 \mathrm{H}_{2} \mathrm{O}\right)$. As quantidades de sais adicionadas foram calculadas a partir dos teores de zinco e cobre encontrados nos lodos.

\subsection{Planta teste}

A planta teste foi o arroz (Oryza sativa), variedade IAC-165.

\subsection{Instalação do Experimento}

\subsubsection{Preparo dos vasos}

O experimento foi conduzido utilizando-se vasos de polietileno providos de reservatório na parte inferior de onde a água adicionada é fornecida ao solo por capilaridade.

Três quilogramas de terra foram colocados nos vasos e, de acordo com esquema de tratamentos apresentado na Tabela 6, foi feita a incorporação dos sais ou lodos. Os

lodos secos ao ar e moídos manualmente foram incorporados aos solos em uma quantidade correspondente a $50 \mathrm{Mg} \mathrm{ha}^{-1} \mathrm{em}$ base seca.

Após um período de 45 dias após a aplicação dos lodos ou sais no solo, realizouse uma amostragem de terra na superficie $(0-5 \mathrm{~cm})$ para cada um dos vasos, para análise de $\mathrm{pH}$ e condutividade elétrica (CE). 
Tabela 6. Tratamentos utilizados no experimento.

\begin{tabular}{cc}
\hline Tratamentos* & Componentes \\
\hline 1 & Solo \\
2 & Solo + lodo $5: 1$ \\
3 & Solo + lodo $7: 1$ \\
4 & Solo + lodo $1: 1$ \\
5 & Solo + lodo 4:1 \\
6 & Solo \\
7 & Solo + sais de $Z n$ e Cu na mesma quantidade presente no lodo $5: 1$ \\
8 & Solo + sais de $Z n$ e Cu na mesma quantidade presente no lodo $7: 1$ \\
9 & Solo + sais de $Z n$ e Cu na mesma quantidade presente no lodo $1: 1$ \\
10 & Solo + sais de $Z n$ e Cu na mesma quantidade presente no lodo $4: 1$ \\
\hline
\end{tabular}

* Os mesmos tratamentos foram utilizados para LV e LE.

\subsubsection{Condução da Cultura}

Após 45 dias de incubação do lodo e sais aos solos foi realizado o plantio. Foram semeadas 20 sementes em cada vaso, e após a germinação procedeu-se o desbaste, deixando quatro plantas por vaso.

$\mathrm{Na}$ ocasião do plantio foram feitas adubações com $\mathrm{N}, \mathrm{P}, \mathrm{K}$ e $\mathrm{S}$, nas doses indicadas na Tabela 7. O cálculo foi baseado nas sugestões de Cantarella \& Furlani (1997). Os fertilizantes minerais utilizados foram: Superfosfato triplo, Cloreto de potássio e Sulfato de cálcio. Foi adicionado $\mathrm{N}$ em cobertura, em quantidade correspondente a $60 \mathrm{~kg} \mathrm{ha}^{-1}$, parcelado em aplicações aos 30 e 50 dias.

As testemunhas não receberam nenhum tipo de adubação. Os tratamentos com lodo e sal receberam a mesma adubação, pois não existe ainda um consenso sobre a quantidade destes macronutrientes fornecida pelo lodo. Sabe-se da deficiência no fornecimento de potássio e estima-se as quantidades fornecidas de $\mathrm{N}$ e P. Uma vez que o 
objetivo do presente estudo não envolve teores de $N, P, K$ e $S$, não foi feita distinção entre os tratamentos.

Tabela 7. Adubações realizadas no plantio.

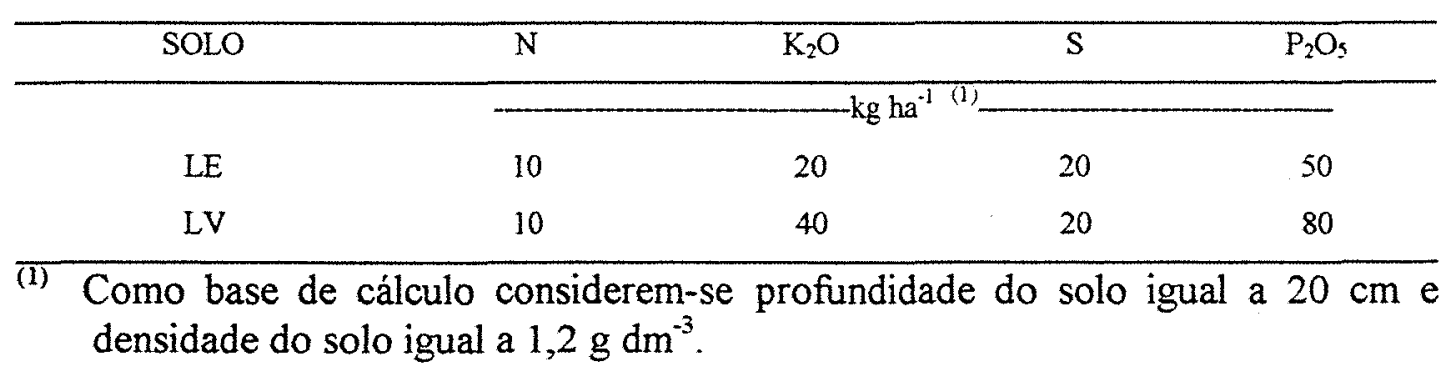

Constatou-se deficiência de $\mathbf{P}$ e $\mathrm{K}$ em todos os tratamentos 65 dias após a emergência, de maneira que nova adubação foi realizada com estes dois nutrientes, seguindo o mesmo procedimento da adubação de plantio. Neste caso, foram adicionados mais $20 \%$ da quantidade recomendada por Cantarella \& Furlani (1997) para cada nutriente.

Esperava-se que a cultura completasse todo seu ciclo, no entanto devido às baixas temperaturas que ocorreram durante o desenvolvimento das plantas, a fase de florescência não teve seu início, de maneira que estas apresentaram apenas desenvolvimento vegetativo.

Quando a cultura atingiu 160 dias foi feito o corte das plantas. O material vegetal colhido, incluindo parte aérea e raiz, foi lavado em água corrente, solução $0,1 \mathrm{~mol} \mathrm{~L}^{-1}$ de $\mathrm{HCl}$ e água deionizada, e após seco a $65^{\circ} \mathrm{C}$, foi pesado para quantificar a massa vegetal produzida; moído em moinho do tipo "Wiley" e analisado para determinação dos teores de $\mathrm{Zn}$ e $\mathrm{Cu}$ em extrato nitro perclórico.

Após o corte das plantas o solo de cada vaso foi homogeneizado. Realizou-se, então, nova amostragem para análise de $\mathrm{pH}$, condutividade elétrica e teores totais e solúveis de $\mathrm{Zn} \mathrm{e} \mathrm{Cu}$. 
3.7 Variáneis avaliadas

3.7.1 pH e condutividade elétrica do solo

$\mathrm{O}$ pH foi determinado em solução $0,01 \mathrm{~mol} \mathrm{~L}^{-1}$ de $\mathrm{CaCl}_{2}$ na proporção solo: solução de $1: 2,5$.

A condutividade elétrica (CE) foi determinada em suspensão solo/água na proporção 1:1 em condutivímetro Digimed CD-21, com largura de célula de $1 \mathrm{~cm}$.

\subsubsection{Teores totais de zinco e cobre}

A extração de $\mathrm{Zn}$ e $\mathrm{Cu}$ totais presentes nos solos foi feita após digestão em forno microondas CEM, modelo MDS-2000, utilizando o extrator água régia, segundo programa descrito por Abreu et al. (1995). A determinação foi feita por espectrofotometria de absorção atômica.

\subsubsection{Fitodisponibilidade de Zn e Cu e extratores para sua analiação}

A fitodisponibilidade de zinco e cobre foi avaliada pela relação entre o teor desses metais no solo e na parte aérea das plantas.

A quantificação nas plantas foi feita por espectrofotometria de absorção atômica após digestão nitro-perclórica, de acordo com a metodologia estabelecida por Sarruge \& Haag (1974).

Os extratores utilizados para avaliação da fitodisponibilidade de zinco e cobre dos solos foram:

- $\mathrm{HCl} 0,1 \mathrm{~mol} \mathrm{~L}^{-1}$ : Método sugerido por Page et al. (1982). Adicionaram-se a $10,0 \mathrm{~g}$ de TFSA $50 \mathrm{~mL}$ de solução $\mathrm{HCl} 0,1 \mathrm{~mol} \mathrm{~L}^{-1}$ e deixou-se em repouso por 24 horas. 
O extrato foi obtido por filtração, utilizando-se papel de filtro Whatman $\mathrm{n}^{0} 1$.

- Mehlich-3 : Metodologia sugerida por Mehlich (1984). Adicionaram-se a 5,0 g de TFSA $50 \mathrm{~mL}$ de Mehlich 3. A solução foi agitada por 5 minutos em agitador mecânico numa velocidade de $240 \mathrm{rpm}$. $O$ extrato foi obtido por filtração, utilizando-se papel de filtro Whatman $n^{\underline{0}} 1$.

- DTPA $0,005 \mathrm{~mol} \mathrm{~L}^{-1} \mathrm{pH} \mathrm{7,3:} \mathrm{Metodologia} \mathrm{sugerida} \mathrm{por} \mathrm{Lindsay} \mathrm{\&} \mathrm{Norvell}$ (1978). Adicionaram-se a $20,0 \mathrm{~g}$ de TFSA $40 \mathrm{~mL}$ de solução extratora. A solução foi agitada por 2 horas em agitador mecânico numa velocidade de $240 \mathrm{rpm}$. O extrato foi obtido por filtração, utilizando-se papel de filtro Whatman $n^{0} 1$.

Todas as determinações foram realizadas por espectrofotometria de absorção atômica.

\subsection{Tratamento estatistico dos dados obtidos}

O experimento foi dividido em duas partes, uma para cada solo, que receberam tratamento estatistico semelhante. $O$ delineamento adotado foi $o$ inteiramente casualizado, onde os tratamentos de cada solo foram agrupados conforme um esquema fatorial $2 \times 5$, ou seja, 2 fontes de metais e 5 relações $\mathrm{Zn}: \mathrm{Cu}$ com 3 repetições. A análise estatística dos resultados foi realizada de acordo com o quadro de análise de variância apresentado na Tabela 8 .

Tabela 8. Modelo de análise de variância.

\begin{tabular}{cc}
\hline Causas de Variação & Graus de Liberdade \\
\hline Fonte & 1 \\
Composição Zn:Cu & 4 \\
Fonte X Composição Zn:Cu & 4 \\
\hline Residuo & 20 \\
\hline Total & 29 \\
\hline
\end{tabular}


Dentro de cada solo, os dados obtidos foram confrontados por meio do teste Tukey de comparação de médias. Para as causas de variação em que a interação foi significativa, analisaram-se os resultados da relação $\mathrm{Zn}: \mathrm{Cu}$ dentro do fator fonte.

Nas tabelas, dentro do capitulo Resultados e discussão, os dados obtidos para os dois solos são apresentados juntos. Para não ocorrer confusão, os dados são separados por uma linha dupla em negrito.

Foram realizadas análises estatísticas de correlação e determinadas equações de regressão entre as quantidades de metais presentes na parte aérea das plantas e as quantidades extraídas dos solos pelos três extratores químicos em estudo.

Com o objetivo de avaliar a influência da interação entre os teores de cobre e zinco, presentes no solo, na absorção destes elementos pela planta, foram realizadas regressões lineares múltiplas envolvendo estas variáveis. 


\section{RESULTADOS E DISCUSSÃO}

\section{1 pH e condutividade elétrica dos solos}

Os valores médios ( 3 repetições) de $\mathrm{pH}$ e condutividade elétrica nas amostras de solos coletadas na ocasião do plantio e após a colheita encontram-se na Tabela 9. Os quadros da análise de variância calculados independentemente para cada um dos solos são apresentados nos Apêndices 1 e 2. Como a dupla interação foi significativa, fez-se o seu desdobramento, de maneira que o teste Tukey foi aplicado para a relação $\mathrm{Zn}: \mathrm{Cu}$ dentro de cada fonte.

Ao comparar as testemunhas com os tratamentos em que os lodos alcalinos foram adicionados, constata-se aumento de $\mathrm{pH}$ do solo após um período de 45 dias de incubação, o mesmo não ocorrendo com o lodo proveniente do tratamento com polieletrólitos, o que reflete a alcalinidade provocada pela adição de cal no sistema gerador dos 3 primeiros lodos. Por ocasião da colheita do arroz, o que corresponde a 205 dias de incubação, os valores de $\mathrm{pH}$ do solo ainda se mantiveram próximos ao observado no plantio.

Alguns autores tem encontrado resultados semelhantes quanto ao aumento de $\mathrm{pH}$ e manutenção do mesmo provocados pela adição de resíduos alcalinos. Sloan \& Basta (1995) realizaram um trabalho estudando a viabilidade da utilização de biosólidos alcalinos para a correção da acidez de solos. Os resultados demonstraram um aumento linear de $\mathrm{pH}$ em relação à taxa de aplicação de lodo de esgoto estabilizado, em diferentes solos, num período de incubação de 180 dias à $25^{\circ} \mathrm{C}$. 
Reis (1998) ao avaliar a variação de $\mathrm{pH}$ provocado por diferentes materiais orgânicos, incubou dois solos por 175 dias com estes materiais. Como resultado encontrou que o lodo de esgoto provocou aumento do $\mathrm{pH}$, que se manteve até o final do período de incubação, sendo este resultado semelhante ao encontrado no presente experimento.

Tabela 9. Valores médios (1) de $\mathrm{pH}$ e condutividade elétrica encontrados nos tratamentos ${ }^{(3)}$.

\begin{tabular}{|c|c|c|c|c|c|c|}
\hline \multirow[t]{3}{*}{ Solos $^{(2)}$} & \multirow[t]{3}{*}{$\begin{array}{c}\text { Fontes de } \mathrm{Zn} \\
\mathrm{e} \mathrm{Cu} \\
\end{array}$} & \multirow[t]{3}{*}{$\begin{array}{c}\text { Relação } \\
\mathrm{Zn}: \mathrm{Cu}\end{array}$} & \multicolumn{2}{|c|}{$\begin{array}{c}\mathrm{pH} \\
\left(\mathrm{CaCl}_{2} 0,01 \mathrm{~mol} \mathrm{~L}^{-1}\right)\end{array}$} & \multicolumn{2}{|c|}{ Condutividade Elétrica } \\
\hline & & & & & $-\mathrm{m} \mathrm{m}$ & $\mathrm{m}^{-1}$ \\
\hline & & & Antes do plantio & Após a colheita & Antes do plantio & Após a colheita \\
\hline \multirow{11}{*}{ LV } & Testemunha. & - & $4,7 \mathrm{a}$ & $4.8 \mathrm{a}$ & $0,51 \mathrm{a}$ & $0.52 \mathrm{a}$ \\
\hline & & $5: 1$ & $6,8 \mathrm{~b}$ & $6,3 \mathrm{~b}$ & $2,78 \mathrm{~d}$ & $2,83 \mathrm{~cd}$ \\
\hline & Lodo & $7: 1$ & $7,0 \mathrm{~b}$ & $6,8 \mathrm{c}$ & $2,90 \mathrm{~d}$ & $2,97 \mathrm{~d}$ \\
\hline & & $1: 1$ & $7,2 \mathrm{~b}$ & $7,0 \mathrm{c}$ & $2,52 \mathrm{c}$ & $2,54 \mathrm{bc}$ \\
\hline & & $4: 1$ & $4,8 \mathrm{a}$ & $4,9 a$ & $2,21 \mathrm{~b}$ & $2,20 \mathrm{~b}$ \\
\hline & Testemunha. & - & $4,7 \mathrm{~A}$ & $4.7 \mathrm{~A}$ & $0.50 \mathrm{~A}$ & $0.53 \mathrm{~A}$ \\
\hline & & $5: 1$ & $4,8 \mathrm{~A}$ & $4,5 \mathrm{~A}$ & $0,93 \mathrm{~B}$ & $0,90 \mathrm{~B}$ \\
\hline & Sal & $7: 1$ & $4,6 \mathrm{~A}$ & $4,5 \mathrm{~A}$ & $0,96 \mathrm{BC}$ & $0,84 \mathrm{AB}$ \\
\hline & & $1: 1$ & $4,5 \mathrm{~A}$ & $4,5 \mathrm{~A}$ & $1,15 \mathrm{C}$ & $0,99 \mathrm{~B}$ \\
\hline & & $4: 1$ & $4,6 \mathrm{~A}$ & $4,5 \mathrm{~A}$ & $0,95 \mathrm{BC}$ & $0,91 \mathrm{~B}$ \\
\hline & C.V. $\%$ & & 3,9 & 2,9 & 4,56 & 2.65 \\
\hline \multirow{11}{*}{ LE } & Testemunha & - & $4,7 \mathrm{a}$ & $4,7 \mathrm{a}$ & $0,44 \mathrm{a}$ & $0,45 \mathrm{a}$ \\
\hline & & $5: 1$ & $6,0 \mathrm{~b}$ & $6,1 \mathrm{~b}$ & $2,38 \mathrm{~b}$ & $2,49 \mathrm{~b}$ \\
\hline & Lodo & $7: 1$ & $6,5 \mathrm{bc}$ & $6,6 \mathrm{~b}$ & $2,97 \mathrm{c}$ & $3,03 \mathrm{c}$ \\
\hline & & $1: 1$ & $6,6 \mathrm{c}$ & $6,6 \mathrm{~b}$ & $2,46 \mathrm{~b}$ & $2,46 \mathrm{~b}$ \\
\hline & & $4: 1$ & $4,7 \mathrm{a}$ & $4,8 \mathrm{a}$ & $2.23 \mathrm{~b}$ & $2.22 \mathrm{~b}$ \\
\hline & Testemunha & & $4.7 \mathrm{~A}$ & $4,7 \mathrm{~A}$ & $0,43 \mathrm{~A}$ & $0,44 \mathrm{~A}$ \\
\hline & & $5: 1$ & $4,4 \mathrm{~A}$ & $4,4 \mathrm{~A}$ & $0,64 \mathrm{AB}$ & $0,57 \mathrm{~A}$ \\
\hline & Sal & $7: 1$ & $4,2 \mathrm{~A}$ & $4,3 \mathrm{~A}$ & $0,71 \mathrm{~B}$ & $0,51 \mathrm{~A}$ \\
\hline & & $1: 1$ & $4,3 \mathrm{~A}$ & $4,3 \mathrm{~A}$ & $0,80 \mathrm{~B}$ & $0,67 \mathrm{~A}$ \\
\hline & & $4: 1$ & $4.3 \mathrm{~A}$ & $4,4 \mathrm{~A}$ & $0,62 \mathrm{AB}$ & $0,45 \mathrm{~A}$ \\
\hline & C.V. $\%$ & & 3,5 & 3,3 & 5,53 & 1.23 \\
\hline
\end{tabular}

(1) Médias seguidas de mesma letra na vertical para fonte sal e lodo separadamente não diferem entre si (Tukey $1 \%$ )

(2) LV refere-se a parte do experimento realizada com Latossolo Vermelho Amarelo e LE com Latossolo Vermelho Escuro

${ }^{(3)}$ Letras minúsculas referem-se aos tratamentos com lodo de esgoto e letras maiúsculas aos tratamentos com sal.

Quanto aos tratamentos com os sais, constata-se que não ocorreram diferenças 
significativas entre os valores de $\mathrm{pH}$ para os dois solos no do período total de incubação.

Para a variável condutividade observa-se um aumento em todos os tratamentos em relação com as testemunhas. Quando lodo foi a fonte de zinco e cobre utilizada, maiores elevações de valores de condutividade elétrica ocorreram, sendo que os tratamentos com sal apresentaram menores incrementos para os dois solos. Provavelmente isto ocorreu por que nos lodos a quantidade de íons é superior à adicionada via sal.

O aumento de condutividade provocado pela adição de lodo já era esperado, uma vez que um dos problemas de sua utilização agrícola é a salinização que este provoca no solo (Cripps \& Matocha, 1991). A salinização ocorre quando se tem uma concentração muito grande de sais no solo, gerando um novo equilibrio osmótico entre a planta e a solução do solo, de maneira que a absorção de nutrientes é muito dificultada. Além disso problemas de toxidez também são comuns nesta situação.

Logan et al. (1997) avaliaram vários parâmetros em um solo com pH 6,1; num experimento de campo, por 4 anos, em que diferentes doses de lodo foram aplicadas no primeiro ano, a saber $0 ; 7,5 ; 15 ; 30 ; 60 ; 90 ; 120 ; 150 ; 188 ; 225$ e $300 \mathrm{Mg} \mathrm{kg}^{-1}$ base seca. A condutividade elétrica aumentou linearmente com a aplicação do lodo, mas iniciou um declínio a partir do segundo ano do experimento. Em comparação com os resultados obtidos no presente trabalho pode-se observar que o comportamento dos valores de condutividade elétrica foi semelhante ao encontrado pelo autor, sendo que o periodo total do experimento (205 dias) provavelmente não foi suficiente para que iniciasse o declínio destes valores.

\subsection{Produção de massa seca da parte aérea e raiz}

Os resultados obtidos para massa seca produzida pelas raizes, parte aérea e total das plantas de arroz são apresentados na Tabela 10. A análise de variância correspondente a estes resultados pode ser observada nos Apêndices 3 e 4 . 
Tabela 10. Produção de massa seca na parte aérea, raiz e total ${ }^{(1)}$ das plantas de arroz (médias de três repetições) $^{(\hat{3})}$.

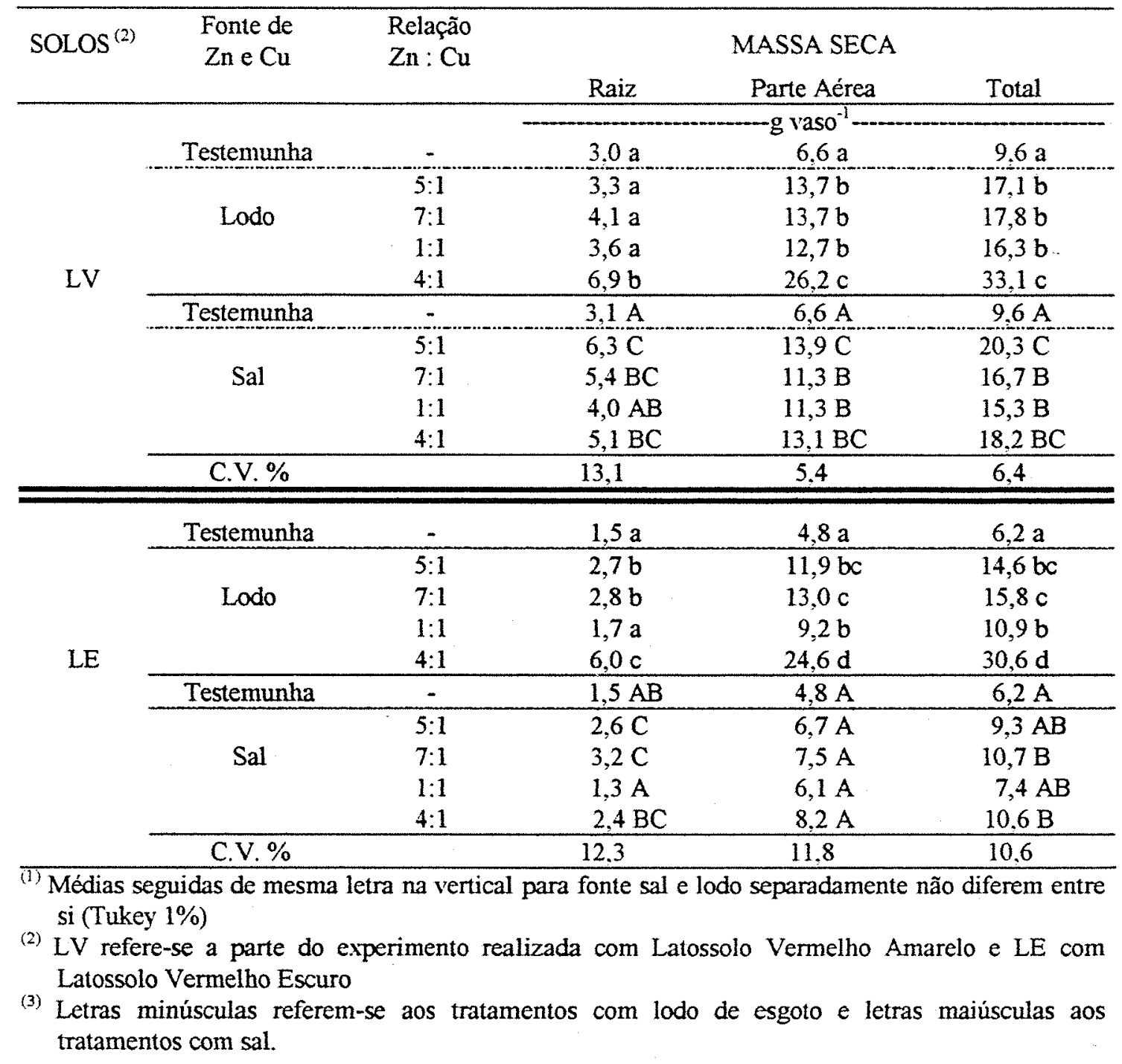

De maneira geral, os tratamentos com lodo tenderam a provocar incrementos maiores na produção de massa seca do que os com sais. Isto se deve ao fato de que o lodo, além de ser fonte de zinco e cobre é também fonte de outros nutrientes, o que não ocorre com o sulfeto de zinco e sulfeto de cobre. Outro fator é a adição de matéria orgânica através do lodo, que provoca mudanças em propriedades químicas, fisicas e biológicas do solo, trazendo vários beneficios para um melhor desenvolvimento da planta 
cultivada sob este solo (Costa et al., 1991; Melo et al., 1994).

Ao analisar a Tabela 10 percebe-se que a quantidade total de massa seca produzida nos tratamentos em que o lodo $4: 1$ foi adicionado nos dois solos foram significativamente maiores do que nos demais tratamentos com lodos. Esta diferença está relacionada com os teores de N, P e K dos lodos. Todos os tratamentos com exceção da testemunha, receberam a mesma adubação, no entanto cada lodo adicionou uma quantidade diferente destes elementos. Observando a Tabela 5, tem-se que os teores de N, P e K do lodo 4:1 são maiores do que dos demais. Desta maneira, as plantas sob o solo destes tratamentos foram beneficiadas em relação às outras.

Outro fato a ser destacado é o de que nos tratamentos em que a relação $\mathrm{Zn}: \mathrm{Cu}$ é de 1:1 no LE, tanto para fonte lodo ou sal, as quantidades de massa seca de raiz produzidas não diferiram da testemunha. Nestes tratamentos constatou-se o aparecimento de clorose na base das folhas e próximo à nervura principal das mesmas. Malavolta (1980) cita este como um sintoma de toxidez de cobre. Um outro sintoma citado é a inibição do crescimento das raizes. Portanto pode-se sugerir que a baixa produção de massa seca da raiz nestes tratamentos deve-se a uma resposta da planta à toxicidade de cobre.

\subsection{Fitodisponibilidade de zinco e cobre}

Os resultados obtidos da absorção tanto de zinco como de cobre pelas plantas são apresentados na Tabela 11. A análise de variância correspondente pode ser observada nos Apêndices 5 e 6.

Para o LV tem-se que o lodo 4:1 forneceu as maiores quantidades de zinco para as plantas, não se diferenciando apenas daquela fornecida pelo lodo 7:1. Lembrando que o lodo 7:1 possui um teor de zinco maior do que o lodo 4:1, o fato dos dois lodos fornecerem as mesmas quantidades não parece correto, porém deve-se levar em conta que a disponibilidade de zinco é incrementada em valores de $\mathrm{pH}$ mais baixos (King \& Hajjar, 1990; Smith, 1994; Oliveira, 1995; Reddy et al., 1995), que foi o caso dos solos 
onde adicionou-se o lodo $4: 1$.

Tabela 11. Teores ${ }^{(1)}$ de zinco e cobre na parte aérea das plantas de arroz (médias de três repetições) $)^{(3)}$.

\begin{tabular}{|c|c|c|c|c|c|}
\hline SOLOS ${ }^{(2)}$ & $\begin{array}{l}\text { Fonte de } \\
\mathrm{Zn} \mathrm{e} \mathrm{Cu}\end{array}$ & $\begin{array}{l}\text { Relação } \\
\mathrm{Zn}: \mathrm{Cu}\end{array}$ & $\mathrm{ZINCO}$ & COBRE & $\begin{array}{c}\text { Relação } \mathrm{Zn}: \mathrm{Cu} \\
\text { na planta }\end{array}$ \\
\hline \multirow{12}{*}{ LV } & & & & & \\
\hline & Testemunha & - & $14 \mathrm{a}$ & $4,5 \mathrm{a}$ & $3: 1$ \\
\hline & \multirow{4}{*}{ Lodo } & $5: 1$ & $27 \mathrm{a}$ & $4,9 \mathrm{a}$ & $6: 1$ \\
\hline & & $7: 1$ & $56 \mathrm{ab}$ & $5,2 \mathrm{a}$ & $11: 1$ \\
\hline & & $1: 1$ & $31 \mathrm{a}$ & $7,6 \mathrm{~b}$ & $4: 1$ \\
\hline & & $4: 1$ & $113 \mathrm{~b}$ & $7,4 b$ & $15: 1$ \\
\hline & Testemunha & - & $14 \mathrm{~A}$ & $4,5 \mathrm{~A}$ & $3: 1$ \\
\hline & \multirow{4}{*}{ Sal } & $5: 1$ & $430 \mathrm{~B}$ & $5,3 \mathrm{AB}$ & $81: 1$ \\
\hline & & $7: 1$ & $741 \mathrm{D}$ & $6,7 \mathrm{~B}$ & $111: 1$ \\
\hline & & $1: 1$ & $522 \mathrm{C}$ & $10,1 \mathrm{C}$ & $52: 1$ \\
\hline & & $4: 1$ & $561 \mathrm{C}$ & $5,6 \mathrm{AB}$ & $101: 1$ \\
\hline & C.V. $\%$ & & 9 & 10,1 & \\
\hline \multirow{11}{*}{ LE } & Testemunha & - & $9 a$ & $5,5 \mathrm{a}$ & $2: 1$ \\
\hline & \multirow{4}{*}{ Lodo } & $5: 1$ & $30 \mathrm{ab}$ & $6.2 \mathrm{ab}$ & $5: 1$ \\
\hline & & $7: 1$ & $57 \mathrm{~b}$ & $67 \mathrm{ab}$ & $9 \cdot 1$ \\
\hline & & $1: 1$ & $67 \mathrm{~b}$ & $87 c$ & $8: 1$ \\
\hline & & $4: 1$ & $117 \mathrm{c}$ & $7,3 \mathrm{~b}$ & $16: 1$ \\
\hline & Testemunha & - & $9 \mathrm{~A}$ & $5,4 \mathrm{~A}$ & $2: 1$ \\
\hline & \multirow{4}{*}{ Sal } & $5: 1$ & $364 \mathrm{~B}$ & $8,3 \mathrm{BC}$ & $44: 1$ \\
\hline & & $7: 1$ & $754 \mathrm{D}$ & $9,3 \mathrm{C}$ & $81: 1$ \\
\hline & & $1: 1$ & $398 \mathrm{~B}$ & $13,0 \mathrm{D}$ & $31: 1$ \\
\hline & & $4: 1$ & $565 \mathrm{C}$ & $7,8 \mathrm{~B}$ & $72: 1$ \\
\hline & C.V. $\%$ & & 6 & 5,9 & \\
\hline
\end{tabular}

(1) Médias seguidas de mesma letra na vertical para fonte sal e lodo separadamente não diferem entre si (Tukey $1 \%$ )

(2) LV refere-se a parte do experimento realizada com Latossolo Vermelho Amarelo e LE com Latossolo Vermelho Escuro

(3) Letras minúsculas referem-se aos tratamentos com lodo de esgoto e letras maiúsculas aos tratamentos com sal.

Outro aspecto a ser salientado é o de que a disponibilidade de zinco é negativamente correlacionada com a saturação de cálcio (Cavallaro \& McBride, 1978; Kabata-Pendias \& Pendias, 1985). Com isso, nos lodos 5:1, 7:1 e 1:1 pode ter ocorrido interação negativa entre estes dois elementos, de maneira que as altas concentrações de cálcio podem ter diminuído a disponibilidade de zinco, acabando por inibir a absorção do mesmo. Isto não foi verificado para o lodo 4:1 que tem menor teor de cálcio (Tabela 5). 
Quando observa-se os resultados obtidos para o LE, tem-se que no tratamento com o lodo 4:1 encontra-se a maior concentração de zinco para as plantas, mesmo quando comparado com o lodo 7:1 que possui maior teor de zinco. Provavelmente, o pH influenciou mais na disponibilidade de zinco no LE em relação ao outro solo.

Para o LV, o teor de zinco na parte aérea das plantas do tratamento com sal 1:1 foi superior ao teor do tratamento 5:1. Uma vez que os dois sais adicionaram quantidades semelhantes de zinco, pode-se sugerir que a presença de altas concentrações de cobre aumentaram a absorção de zinco por plantas sob este solo. O mesmo não ocorreu com o tratamento correspondente com lodo pois outros fatores estão afetando a disponibilidade, como matéria orgânica, presença de outros metais, entre outros.

Nos tratamentos com sais no LE os teores de zinco encontrados na parte aérea das plantas refletiram as quantidades adicionadas.

Quanto ao cobre, no LV as quantidades absorvidas pela parte aérea das plantas nos tratamentos com o lodo 5:1 e 7:1 não diferiram significativamente da testemunha. Já para o lodo 1:1 e 4:1 a absorção foi maior. Considerando que as quantidades adicionadas de cobre pelo lodo $7: 1$ foram semelhantes às adicionadas pelo lodo $4: 1$, a diferença entre os dois tratamentos pode ser atribuída ao valor de $\mathrm{pH}$ do solo menor no tratamento com lodo 4:1 resultando numa maior disponibilidade de cobre (Alloway, 1991; Smith, 1994; Oliveira, 1995; Reddy et al., 1995). A mesma explicação pode ser dada quando se compara o lodo $1: 1$ e 4:1, pois o primeiro forneceu cerca de três vezes mais cobre do que o segundo, no entanto ao comparar os teores nas plantas não se tem diferença significativa entre os dois tratamentos.

Outro fator que pode ter influído na disponibilidade de cobre é a qualidade da matéria orgânica fornecida pelo lodo. $\mathrm{O}$ cobre é um elemento que apresenta grande tendência a formar complexos estáveis com ligantes orgânicos (Colleman, 1956; Holtzclaw et al., 1978; Chino et al., 1992; Kreij et al., 1993; Rodella, 1993 e MattiazzoPrezotto, 1994). Dependendo do tipo de complexo orgânico formado, o cobre pode ficar numa forma solúvel ou insolúvel. Alguns autores como Kabata-Pendias \& Pendias (1985) citam que o peso molecular do complexo formado determina a solubilidade do mesmo. 
Comparando-se as relações $\mathrm{C} / \mathrm{N}$ dos vários lodos, observa-se que o lodo $4: 1$ apresenta uma relação igual a cinco em quanto os outros lodos apresentam relação igual a dez. Isto sugere que o lodo 4:1 é um material orgânico diferente dos demais, podendo formar complexos com cobre também diferentes, talvez mais solúveis do que os formados nos outros tratamentos com lodo. Este fato evidencia a importância do sistema de tratamento gerador do lodo, que é a principal diferença entre o lodo em questão e os demais.

O tratamento com o lodo 1:1 no LE apresentou maior teor de cobre na parte aérea das plantas. Isto já era esperado uma vez que este resíduo adicionou maior quantidade de cobre ao solo. No LV o pH foi um fator de maior importância, uma vez que alterou o resultado esperado.

Nos tratamentos com sais no LV os teores de cobre encontrados na parte aérea das plantas refletiram as quantidades adicionadas. Já para o LE, os teores de cobre encontrados na parte aérea das plantas do tratamento com sal 4:1 deveriam ter sido semelhantes aos encontrados nos tratamentos com sal 7:1, pois os dois adicionaram quantidades semelhantes de cobre. Pode-se sugerir que a presença de altas concentrações de zinco aumentaram a absorção de cobre por plantas sob este solo.

Um fato a ser ressaltado é o de que quando se compara os teores de zinco absorvidos nos tratamentos com sal em relação aos com lodo, a diferença é muito acentuada, pois os tratamentos com sal apresentam teores de zinco muito maiores do que os com lodo. Já para o cobre, esta diferença é bem menos perceptível.

Kabata-Pendias \& Pendias (1985) relatam que normalmente os tecidos da raiz das plantas possuem grande capacidade de retenção de cobre, evitando sua translocação para a parte aérea em situações de toxidez. Apesar das plantas normalmente apresentarem maiores teores de zinco na raiz, em caso de toxidez a translocação do elemento para a parte aérea ocorreria normalmente. Portanto, quando os dois elementos estiverem no solo em altas quantidades, proporcionalmente, maior teor de zinco do que de cobre será encontrado na parte aérea.

Dos resultados obtidos, pode-se inferir que apenas nos tratamentos com sal os 
teores atingiram niveis prejudiciais para as plantas de acordo com Kiekens (1990), apesar destas não terem apresentado nenhum sintoma de toxidez.

Para cobre, Baker (1990) citou que a concentração nas plantas compreende o intervalo de 5 a $20 \mathrm{mg} \mathrm{kg}^{-1}$ de Cu na matéria seca, podendo ocorrer variações em que os teores atingem os extremos de 1 a $30 \mathrm{mg} \mathrm{kg}^{-1}$ de $\mathrm{Cu}$. Todos os teores obtidos encontramse nesta faixa. No entanto no LE, para a relação $1: 1$, não importando a fonte utilizada, ocorreram sintomas de toxidez, sendo que os teores encontrados foram de $9 \mathrm{mg} \mathrm{kg}^{-1}$ para lodo e $13 \mathrm{mg} \mathrm{kg}^{-1}$ para sal.

A relação $\mathrm{Zn}: \mathrm{Cu}$ usual nas plantas é de aproximadamente $5 \mathrm{Zn}: 1 \mathrm{Cu}$ (cálculo baseado nos teores médios citados por Kiekens, 1990 e Baker, 1990). Nos tratamentos com lodo, observa-se que esta relação foi mantida apenas quando o lodo $5: 1$ foi adicionado. Para os outros lodos, a relação foi alterada, principalmente quando o lodo 4:1 foi adicionado em que a relação atingiu a proporção de 15:1 no LV e 16:1 no LE. Apesar de apresentar a relação alterada não se notou sintomas de deficiência nem de toxidez para nenhum dos elementos nos tratamentos com as relações mais altas. É importante o fato de que em valores de $\mathrm{pH}$ do solo mais altos a relação $\mathrm{Zn}: \mathrm{Cu}$ do lodo indica o comportamento da relação na planta. Ou seja, pode-se inferir que em solos com valores de $\mathrm{pH}$ em torno de 7 a relação $\mathrm{Zn}: \mathrm{Cu}$ da planta reflete a relação do lodo adicionado.

Para os tratamentos com sal estas relações apresentaram um aumento mais acentuado, chegando a atingir a proporção de 111 de $\mathrm{Zn}: 1$ de $\mathrm{Cu}$. Também neste caso não ocorreram sintomas de deficiência ou toxidez. Como já foi discutido, apenas no LE, nos tratamentos com adição de lodo $1: 1$ e sal 1:1, ocorreram sintomas de toxidez de cobre. As relações nas plantas encontradas para estes tratamentos foram 8:1 e 31:1, respectivamente. 


\subsection{Extratores quimicos}

Os valores médios dos teores de zinco e cobre extraidos por $\mathrm{HCl} 0,1 \mathrm{~mol} \mathrm{~L}^{-1}$, Mehlich-3, DTPA e Água régia encontram-se nos Apêndices 7 e 8. Os quadros de análise de variância correspondentes, calculados independentemente para cada um dos solos, são apresentados nos Apêndices 9 e 10.

Com o intuito de determinar para cada elemento estudado o extrator que melhor reflete a fitodisponibilidade, foram calculadas, para todos os tratamentos, correlações e regressões lineares simples entre os teores encontrados nas plantas e os removidos por cada um dos extratores, com exceção da água régia que determina o teor total. As equações encontradas, bem como os coeficientes de determinação e correlação, são apresentados na Tabela 12 .

Tabela 12. Equações de regressão e respectivos coeficientes de determinação $\left(R^{2}\right)$ e correlação ( $\mathrm{r}$ ) entre os teores de $\mathrm{Zn}$ e Cu removidos pelos extratores (x) e os teores encontrados na parte aérea das plantas (y).

\begin{tabular}{|c|c|c|c|c|}
\hline Solos & Variáveis & Equação & $\mathrm{R}^{2}$ & $\mathrm{r}$ \\
\hline \multirow{6}{*}{ LV } & $\mathrm{Zn}$ (planta) $\times \mathrm{Zn}(\mathrm{HCl})$ & $Y=12,094+0,193 X$ & 0,784 & 0,885 \\
\hline & Zn (planta) $\times \operatorname{Zn}$ (Mehlich-3) & $Y=4,383+0,235 X$ & 0,805 & 0,897 \\
\hline & $\mathrm{Zn}$ (planta) $\times \mathrm{Zn}$ (DTPA) & $Y=3,882+0,140 X$ & 0,859 & 0,927 \\
\hline & $\mathrm{Cu}$ (planta) $\times \mathrm{Cu}(\mathrm{HCl})$ & $Y=-43,201+9,379 X$ & 0,714 & 0,845 \\
\hline & $\mathrm{Cu}$ (planta) $\times \mathrm{Cu}$ (Mehlich-3) & $Y=-60,945+13,568 X$ & 0,710 & 0,842 \\
\hline & $\mathrm{Cu}$ (planta) x Cu (DTPA) & $Y=-52,357+11,155 X$ & 0,719 & 0,848 \\
\hline \multirow{6}{*}{ LE } & $\mathrm{Zn}$ (planta) $\times \mathrm{Zn}(\mathrm{HCl})$ & $Y=11,445+0,188 X$ & 0,867 & 0,931 \\
\hline & Zn (planta) $\times$ Zn (Mehlich-3) & $Y=10,803+0,164 X$ & 0,841 & 0,917 \\
\hline & $\operatorname{Zn}($ planta $) \times \operatorname{Zn}(\mathrm{DTPA})$ & $Y=7,837+0,087 X$ & 0,862 & 0,928 \\
\hline & $\mathrm{Cu}$ (planta) $\times \mathrm{Cu}(\mathrm{HCl})$ & $Y=-37,142+6,557 X$ & 0.896 & 0,946 \\
\hline & $\mathrm{Cu}$ (planta) $\times \mathrm{Cu}$ (Mehlich-3) & $Y=-44,358+8,214 X$ & 0,757 & 0,868 \\
\hline & $\mathrm{Cu}$ (planta) x $\mathrm{Cu}(\mathrm{DTPA})$ & $Y=-36,800+6,320 X$ & 0,850 & 0,922 \\
\hline
\end{tabular}

A partir dos dados mostrados na Tabela 12 constata-se que os valores dos coeficientes de determinação estão muito próximos, de maneira que a escolha de apenas um extrator para cada elemento e cada solo através da análise destes coeficientes é 
dificultada. Pode-se então inferir que todos os extratores são representativos da fitodisponibilidade de zinco e cobre nas concentrações estudadas. Isto provavelmente tenha ocorrido por que as quantidades de zinco e cobre adionadas ao solo no presente experimento foram todas altas.

Um fator importante que pode ser levado em consideração na escolha do melhor extrator é a operacionalidade do método de extração (Schung, 1996). Uma vez que os coeficientes de correlação e determinação foram semelhantes, pode-se optar pelo $\mathrm{HCl} 0,1$ mol L ${ }^{-1}$ que é o mais simples operacionalmente.

Para a extração de micronutrientes no Estado de São Paulo foi oficialmente adotado o DTPA em 1993 (Abreu et al., 1994). O método de extração com DTPA, em relação aos demais extratores, é o menos operacional. Além disso, a capacidade de remoção do DTPA depende de vários fatores como pH do solo (Camargo et al. 1982) e mineralogia do solo (Fagbami et al., 1985). Esta escolha deve ter sido feita baseada em resultados obtidos com experimentos em que os teores de zinco e cobre no solo eram inferiores aos do presente experimento.

É importante lembrar que o fato dos coeficientes de determinação indicarem que os três extratores podem ser utilizados não é uma constante, uma vez que dependendo do tipo de solo, da cultura, do metal em questão e da fonte deste metal varia o extrator que melhor representa a fitodisponibilidade (Bertoncini, 1997). A todos estes fatores poderia ainda ser adicionado os teores dos metais no solo.

\subsection{Interação entre zinco e cobre}

A influência da interação entre os teores de zinco e cobre presentes no solo na absorção destes elementos pela planta foi avaliada pela análise dos coeficientes das regressões lineares múltiplas envolvendo estas variáveis.

Apesar de qualquer um dos três extratores avaliados serem representativos dos teores de zinco e cobre fitodisponiveis no solo, apenas um deles foi utilizado nas 
regressões múltiplas. Optou-se, então, pelos extratores com os maiores coeficientes de determinação. Portanto utilizou-se DTPA para o LV e $\mathrm{HCl} 0,1 \mathrm{~mol} \mathrm{~L}^{-1}$ para o LE.

As equações de regressão, bem como os coeficientes de determinação são apresentados na Tabela 13. Os modelos matemáticos adotados foram os seguintes:

$\rightarrow \quad \mathrm{ZnPl}=\beta_{0}+\beta_{1} \mathrm{ZnEx}+\beta_{2} \mathrm{CuEx}+\beta_{3} \mathrm{ZnCu}$

Onde:

$\mathrm{ZnPl}=$ Teor de zinco na parte aérea da planta;

$\mathrm{ZnEx}=$ Teor de zinco removido pelo extrator;

$\mathrm{CuEx}=$ Teor de cobre removido pelo extrator;

$\mathrm{ZnCu}=$ Interação entre Zinco e Cobre removidos pelo extrator.

$\rightarrow \quad \mathrm{CuPl}=\beta_{0}+\beta_{1} \mathrm{ZnEx}+\beta_{2} \mathrm{CuEx}+\beta_{3} \mathrm{ZnCu}$

Onde:

$\mathrm{CuPl}=$ Teor de cobre na parte aérea da planta;

$\mathrm{ZnEx}=$ Teor de zinco removido pelo extrator;

$\mathrm{CuEx}=$ Teor de cobre removido pelo extrator.

$\mathrm{ZnCu}=$ Interação entre Zinco e Cobre removidos pelo extrator.

Tabela 13. Equações de regressão entre as quantidades de zinco e cobre removidas pelos extratores e os teores de zinco e cobre encontrados na parte aérea das plantas e respectivos coeficientes de determinação $\left(R^{2}\right)$.

\begin{tabular}{cccc}
\hline Solos & Variável dependente & Equação & $\mathrm{R}^{2}$ \\
\hline LV & ZnPl & $\mathrm{Y}=-3,652+4,960 \mathrm{X}_{1}+0,817 \mathrm{X}_{2}+0,056 \mathrm{X}_{3}$ & 0,931 \\
& $\mathrm{CuPl}$ & $\mathrm{Y}=4,706+0,014 \mathrm{X}_{1}+0,101 \mathrm{X}_{2}-0,001 \mathrm{X}_{3}$ & 0,747 \\
\hline $\mathrm{LE}$ & $\mathrm{ZnPl}$ & $\mathrm{Y}=-5,454+3,195 \mathrm{X}_{1}-1,409 \mathrm{X}_{2}+0,081 \mathrm{X}_{3}$ & 0,905 \\
& $\mathrm{CuPl}$ & $\mathrm{Y}=5,385+0,013 \mathrm{X}_{1}+0,144 \mathrm{X}_{2}+0,000 \mathrm{X}_{3}$ & 0,932 \\
\hline
\end{tabular}

Para os dois solos, nas equações de regressão em que a variável dependente é o 
como o de Butley \& Bray (1956) e Chew et al. (1979) mostraram um aumento da absorção de cobre na presença de zinco e vice-versa. Porém nestes trabalhos, a interação positiva ocorreu com muito mais significância do que no presente estudo.

Concluiu-se que a influência de zinco no solo sobre a absorção de cobre pela planta e vice versa é pouco significativa não devendo ser considerada no modelo matemático. Tem-se, então, que nas concentrações estudadas não houve efeito de zinco no solo sobre a absorção de cobre pela planta, sendo que o contrário também é válido. É importante ressaltar que tanto para zinco como para cobre as concentrações eram altas em todos tratamentos, portanto em experimentos que um destes elementos esteja com o teor mais baixo pode ser que o resultado da interação seja diferente. 
teor de zinco na planta, os valores numéricos de $\beta_{2}$ e $\beta_{3}$, que são multiplicados pelo cobre removido pelo extrator e pela interação respectivamente, são positivos. Portanto, tem-se que quanto mais cobre disponivel, mais zinco é absorvido nas proporções indicadas pelo modelo matemático e pela significância dos respectivos coeficientes. $\mathrm{O}$ mesmo ocorreu com o cobre absorvido pelas plantas em relação ao zinco removido pelo extrator.

Os coeficientes $\beta_{3}$ nos dois solos e para os dois elementos são muito baixos, de maneira que quando multiplicados pela interação não provocarão grandes alterações no valor da variável dependente ( $\mathrm{ZnPl}$ ou $\mathrm{CuPl})$. Da mesma maneira, nas equações em que a variável dependente é o $\mathrm{ZnPl}$, o coeficiente do $\mathrm{CuEx}$ é bem menor em relação ao do $\mathrm{ZnEx}$ e também não deve provocar grandes alterações no valor final do $\mathrm{ZnPl}$. Para CuPl, o mesmo ocorreu com os coeficientes de $\mathrm{ZnEx}$ em relação aos de $\mathrm{CuEx}$.

Para avaliar a significância de cada variável independente dentro da equação foi utilizado como parâmetro o valor de F, apresentado na Tabela 14 .

Tabela 14. Modelos matemáticos utilizados e respectivos valores de $F$ para os coeficientes de cada variável dependente.

\begin{tabular}{lcrrr}
\hline Solos & Modelo & \multicolumn{3}{c}{ Valor de F do coeficiente } \\
& Matemático & ZnExtrator & CuExtrator & ZnCu \\
\hline $\mathrm{LV}$ & $\mathrm{ZnPl}=\beta_{0}+\beta_{1} \mathrm{Zn} \mathrm{DTPA}+\beta_{2} \mathrm{CuDTPA}+\beta_{3} \mathrm{ZnCu}$ & 322,38 & 25,33 & 1,58 \\
& $\mathrm{CuPl}=\beta_{0}+\beta_{1} \mathrm{Zn} \mathrm{DTPA}+\beta_{2} \mathrm{CuDTPA}+\beta_{3} \mathrm{ZnCu}$ & 5,70 & 68,42 & 2,69 \\
\hline $\mathrm{LE} \quad \mathrm{ZnPl}=\beta_{0}+\beta_{1} \mathrm{Zn} \mathrm{HCl}+\beta_{2} \mathrm{CuHCl}+\beta_{3} \mathrm{ZnCu}$ & 236,90 & 7,42 & 3,08 \\
& $\mathrm{CuPl}=\beta_{0}+\beta_{1} \mathrm{Zn} \mathrm{HCl}+\beta_{2} \mathrm{CuHCl}+\beta_{3} \mathrm{ZnCu}$ & 6,47 & 55,95 & 1,06 \\
\hline
\end{tabular}

Ao analisar os valores de $\mathrm{F}$ para cada solo e elemento estudado tem-se que a significância da interação é muito pequena em relação aos outros coeficientes, de maneira que esta poderia ser excluída do modelo matemático.

Tanto para o LV como para o LE, a influência de CuEx no resultado de ZnPl é pequena, o mesmo para a influência de $\mathrm{ZnEx}$ no resultado de CuPl. Alguns trabalhos 


\section{CONCLUSÕES}

Os resultados obtidos no presente estudo permitiram concluir que:

- A disponibilidade de zinco e cobre adicionados via lodo e sal foi diferente em função da fonte utilizada, nos dois solos;

- O sistema de tratamento gerador do lodo de esgoto influi na disponibilidade de zinco e cobre adicionados ao solo via este resíduo;

- Para os dois solos tanto o DTPA, como o $\mathrm{HCl} 0,1 \mathrm{~mol} \mathrm{~L}^{-1}$ e o Mehlich-3 foram representativos da fitodisponibilidade de zinco e cobre;

- Não houve efeito significativo de zinco no solo sobre a absorção de cobre pela planta e vice versa;

- São necessários mais estudos envolvendo vários solos tropicais e composições $\mathrm{Zn}: \mathrm{Cu}$ em um número que permita a quantidade de pontos necessária para a determinação de um modelo matemático que represente com segurança a influência de um metal sobre o outro. 


\section{REFERÊNCIAS BIBLIOGRÁFICAS}

ABREU, C.A. de; RAIJ, B.van; ABREU, M.F.de. Análise de micronutrientes em solos, o lucro certo. O Agronômico, v.46, p.7-8, 1994.

ABREU, C.A. de; ABREU, M.F.de; RAIJ, B.van; SANTOS, W.R. Comparação de métodos de análise para avaliar a disponibilidade de metais pesados em solos. Revista Brasileira de Ciência do Solo, v.19, p.463-468, 1995.

ALLOWAY, B.J. Heavy metals in soils. New York: John Wiley, 1990. 339p.

ARORA, C.L.; SEKHON, G.S. The effect of soil characteristics on the zinc-copper interaction in the nutrition of wheat. Journal of Agricultural Science, v.99, p.185189, 1982.

ARTEAGA, D.H. Dinâmica de cádmio, chumbo, cobre, níquel e zinco no sistema soloplanta. Viçosa, 1996. 90p. Dissertação (Mestrado) - Universidade Federal de Viçosa.

BAKER, D.E. Copper. In: ALLOWAY, B.J. Heavy metals in soils. New York: John Wiley, 1990. cap.8, p.152-176.

BARBOSA FILHO, M.P.; DYNIA, J.F.; ZIMMERMANN, F.J.P. Resposta do arroz de sequeiro ao zinco e ao cobre com efeito residual para o milho. Revista Brasileira de Ciência do Solo, v.14, p.333-338, 1990. 
BARRETTO, M.C. de. Degradação da carga orgânica de diferentes resíduos e seus efeitos em alguns atributos químicos e físicos do solo. Piracicaba, 1995. 106p. Tese (Doutorado) - Escola Superior de Agricultura "Luiz de Queiroz", Universidade de São Paulo.

BERTON, R.S.; CAMARGO, O.A.; VALADARES, J.M.A.S. Absorção de nutrientes pelo milho em resposta à adição de lodo de esgoto a cinco solos paulistas. Revista Brasileira de Ciência do Solo, v.13, n.2, p. 187-192, 1989.

BERTONCINI, E.I. Mobilidade de metais pesados em solos tratados com lodo de esgoto. Piracicaba, 1997. 102 p. Dissertação (Mestrado) - Escola Superior de Agricultura "Luiz de Queiroz", Universidade de São Paulo.

BRAR, M.S.; SEKHON, G.S. Effect of zinc and copper application on the yield and micronutrient content of wheat. Journal of Indian Society of Soil Science, v.26, p. $84-86,1978$.

BUNTING, A.H. Experiments on organic manures. Journal of Agricultural Science, v. 60, p. 121-140, 1963.

BUTLEY, P.C.; BRAY, R.H. Effect of the zinc chelate of EDTA on plant uptake of zinc and other heavy metals. Soil Science Society of America Proceedings, v.20, p.348-351, 1956.

CAMARGO, O.A.; VALADARES, J.M.A.S.; DECHEN, R.A. Efeitos do pH e da incubação na extração do manganês, zinco, cobre e ferro do solo. Revista Brasileira de Ciência do Solo, v.6, p.83-88, 1982. 
CANTARELlA, H., FURLANI, P.R. Arroz de sequeiro. In: RAIJ, B. Van. Recomendações de calagem para o Estado de São Paulo. Campinas: IAC, 1997. 285 p. (IAC, Boletim Técnico, 100).

CASTILLO, I.T.J. DEL; PEREZ, A.B.; JEREZ, F.G. Capacidad de adsorcion de Cu y $\mathrm{Zn}$ de suelos desarrollados bajo tres tipos de vegetation. I. Anales de Edafología y Agrobiología, v.39, p.935-944, 1980.

CAVALLARO, N.; McBRIDE, M.B. Copper and cadmium adsorption characteristics of selected acid and calcareous soils. Soil Science Society of America Journal, v.42, p.550-556, 1978 .

CHAUDHRY, F.M.; LONERAGAN, J.F. Effects of nitrogen, copper and zinc fertilizers on the copper and zinc nutrition of wheat plants. Australian Journal of Agricultural Research, v.21, p.865-879, 1970.

CHEW, W.Y.; JOSEPH, K.T.; RAMLI, K. Influence of applied copper and other micronutrients on groundnuts (Arachis hypogaea) and sorghum (Sorghum bicolor) on Malaysian oligotrophic peat. Tropical Agriculture, v.56, p.25-32, 1979.

CHINO, M.; GOTO, S.; KUMAZAWA, K.; OWA, N. et al. Behavior of zinc and copper in soil with long-term application of sewage sludge. Soil Science and Plant Nutrition, v.38, n. 1, p.159-167, 1992.

CHUKWUMA, C. Evaluating baseline data for copper, manganese, nickel and zinc in rice, yam, cassava and guinea grass from cultivated soils in Nigeria. Agriculture, Ecosystems and Environment, v.53, p.47-61, 1995. 
COLLEMAN, N.T., McLUNG, A.C., MOORE, D.P. Formation constants for Cu (II) Peat. Science,v.123, p.330-331, 1956.

COSTA,F; GARCIA, C.; HERNANDÉZ, T; POLO, A. Residuos orgánicos urbanos. In: CSIC (Ed.). Manejo y Utilización, Murcia: Murcia University, 1991. p. 87-108.

CRIPPS, R.W; MATOCHA, J.E. Effect of sewage sludge application to ameliorate iron deficiency of grain sorghum. Communications in Soil Science and Plant Analysis, v.22, p.1931-1940, 1991.

CRUZ, M.C.P. da; FERREIRA, M.E. Seleção de métodos para avaliação do cobre disponivel nos solos. Pesquisa Agropecuária Brasileira, v.25, p.647-659, 1990.

DECHEN, A. R.; HAAG, H.P.; CARMELLO, Q.A. de C. Micronutrientes na planta. In: FERREIRA, M.E; CRUZ, M.C. P. da. Micronutrientes na agricultura. Piracicaba: POTAFOS, 1991. cap.3, p.65-75.

DİAZ-BURGOS,M.A.; POLO, A. Variaciones de la fracción orgánica durante el compostaje de lodos de depuradoras. Suelo y Planta, v.1, p.453-466, 1991.

FAGBAMI, A.; AJAYI, S.O; ALI, E.M. Nutrient distribution in the basament complex soils of the tropical, dry rainforest of southwetern Nigeria: 2. Micronutrients - zinc and copper. Soil Science, v.139, p.531-537, 1985.

HADDAD, K.S.; EVANS, J.C. Assessment of chemical methods for extracting zinc, manganese, copper and iron from new south wales soils. Communications in Soil Science and Plant Analysis, v.24, p.29-44, 1993. 
HOLTZCLAW, K.M.; KEECH, D.A.; PAGE, A.L.; SPOSITO, G. et al. Trace metals distribution among the humic acid, the fulvic acid and precipitable fractions extracted with sodium hydroxide from sewage sludge. Journal of Environmental Quality, v.7, p. 124-127, 1978.

JALALI, V.K.; TAKKAR, P.N. Evaluation of parameters for simultaneous determination of cations available to plants from soils. Indian Journal of Agricultural Sciences, v.49, p.622-626, 1979.

KABATA-PENDIAS, A.; PENDIAS, $H$. Trace elements in soils and plants. 3. ed. Boca Raton: CRP Press, 1985. 315 p.

KELLER, C.; VÉDY, J.C. Distribuition of copper and cadmium fractions in two forest soils. Journal of Environmental Quality, v.23, n.5, p.987-999, 1994.

KIEKENS, L. Zinc. In: ALLOWAY, B.J. Heavy metals in soils. New York: John Wiley, 1990. cap.13, p.261-279.

KING, L.D.; HAJJAR, L.M. The residual effect of sewage sludge on heavy metal content of tobacco and peanut. Journal of Environmental Quality, v.19, p.738$748,1990$.

KREIJ, C.; MARTIGNON, G.; VAN ELDEREN, C.W. Comparasion of water, DTPA and nitric acid as extractants to assess theavailability of copper in peat substracts. Comminications in Soil Science and Plant Analysis, v.24, p.227-236, 1993.

LADONIN, D.V;; MARGOLINA, S.E. Interaction between humic acids and heavy metals. Eurasian Soil Science, v.30, p.710-715, 1997. 
LÈON, L.A.; LOPES, A.S.; VLEK, P.L.G. Micronutrient problems in tropical Latin America. Fertilizer Research, v.7, p.95-129, 1985.

LEPP,N.W.; DICKINSON, M.N.; ORMAND, K.L. Distribution of fungicide-derived copper in soils and vegetation of different aged stands of coffee (Coffea arabica L.) in Kenya. Plant and Soil, v.77, p.263-270, 1984.

LIDON, F.C.; HENRIQUES, F.S. Effects of copper toxicity on growth and the uptake and translocation of metals in rice plants. Journal of Plant Nutrition, v.16, p.1449$1464,1990$.

LINDSAY, W.L.; HOIWELL, W.A. Development of DTPA soil test for zinc, iron, manganese and copper. Soil Science Society of America Journal, v.42, p.421-428, 1978.

LOGAN, T.J.; CHANEY, R.L. Metals. In: PAGE, A.L.; GEASON, T.L.; SMITH, J.E.; ISKANDAR, J.K; SOMMERS, L.E. (Ed.). Utilization of municipal wastewater and sludge on land. Riverside: University of California, 1983 p. 79-103.

LOGAN, T.J.; LINDSAY, B.J.; GOINS; L.E.; RYAN, J.A. Field assessment of sludge metal bioavailability to crops: sludge rate response. Journal of Environmental Quality, v.26, p.534-550, 1997.

MALAVOLTA, E. Elementos de nutrição mineral de plantas. São Paulo: Agronômica Ceres, 1980. 251 p.

MATTIAZZO-PREZOTTO, M.E. Química ambiental e agronomia. In: REUNIÃO BRASILEIRA DE CIÊNCIA DO SOLO, 20., Piracicaba, 1992. Anais. Campinas: Fundação Cargill, 1992. p.157-178. 
MATTIAZZO-PREZOTTO, M.E. Comportamento de cobre, cádmio, crômio, níquel e zinco adicionados a solos de clima tropical em diferentes valores de $\mathrm{pH}$. Piracicaba, 1994. 197 p. Tese (Livre Docência) - Escola Superior de Agricultura "Luiz de Queiroz", Universidade de São Paulo.

McGRATH, S.P.; CEGARRA, J. Chemical extractability of heavy metals during and after long-term application of sewage sludge to soil. Journal of Soil Science, v.43, p.313-321, 1992.

MEHLICH, A. Mehlich 3 soil test extractant: a modification of Mehlich 2 extractant. Communications in Soil Science and Plant Analysis, v.15, p. 1409-1416, 1984.

MELO, W.J.; MARQUES, M.O; SANTIAGO, G.; CHELLI, R.A.; LEITE, S.A.S. Efeito de doses crescentes de lodo de esgoto sobre frações de matéria orgânica e CTC de um latossolo cultivado com cana-de-açúcar. Revista Brasileira de Ciência do Solo, v.18, p.449-455, 1994.

MESQUITA, M.E.; SILVA, J.M.V.e. Zinc adsorption by a calcareous soil. Copper interaction. Geoderma, v.69, p.137-146, 1996.

MOUSSA, B.I.M; DAHDOH, M.S.A; SHEHATA, H.M. Interaction effect of some micronutrients on yield, elemental composition and oil content of peanut. Communications in Soil Science and Plant Analysis, v.27, p. 1995-2004, 1996.

OLIVEIRA, F.C. Comportamento de metais pesados e formas nitrogenadas em solos tratados com lodo de esgoto. Piracicaba, 1995. 91 p. Dissertação (Mestrado) Escola Superior de Agricultura "Luiz de Queiroz", Universidade de São Paulo. 
OLIVEIRA, F.C.; MARQUES, M.O.; BELLINGIERI, P.A.; PERECIN, D. Lodo de esgoto como fonte de macronutrientes para a cultura do sorgo granifero. Scientia Agricola, v.52, p.360-367, 1995.

PAGE, A.L.; MILLER, P.H.; KEENEY, D.F. Methods of soil analysis 2. ed., Madison: ASA; SSSA, 1982. 1159p.

PEDREÑO, J.N.; GOMEZ, I.; MORAL, R.; MATAIX, J. Improving the agricultural value of a semi-arid soil by addition of sewage sludge and almond residue. Agriculture Ecosystem \& Environment, v.58, n.2-3, p.115-119, 1996.

RAIJ, B. van. Geoquímica de micronutrientes. In: FERREIRA, M.E.; CRUZ, M.C. P. da. Micronutrientes na agricultura. Piracicaba: POTAFÓS, 1991. cap.4, p.99110.

RAIJ, B. van; QUAGGIO, J.A. Métodos de análise de solo para fins de fertilidade. Campinas: IAC, 1983. 40 p. (IAC.Boletim Técnico, 81).

REDDY, K.J.; WANG, L.; GLOSS, S.P. Solubility and mobility of copper, zinc and lead in acidic environments. Plant and Soil, v.171, p.53-58, 1995.

REIS, T.C. Variação da acidez do solo em função da adição de diferentes materiais orgânicos. Piracicaba, 1998. 65 p. Dissertação (Mestrado) - Escola Superior de Agricultura "Luiz de Queiroz", Universidade de São Paulo.

RITCHEY, K.D.; COX, F.R.; GALRÃO, E.Z.; YOST, R.S. Disponibilidade de zinco para as culturas do milho, sorgo e soja em Latossolo Vermelho-Escuro argiloso. Pesquisa Agropecuária Brasileira, v.21, p.215-225, 1986. 
RODELLA, A.A. Determinação espectrofotométrica automatizada de cobre e zinco em amostras de interesse agroindustrial por métodos cinéticos. Campinas, $1993.132 \mathrm{p}$. Tese (Doutorado) - Instituto de Química, Universidade de Campinas.

SARRUGE, J.R.; HAAG, H.P. Análises químicas em plantas. Piracicaba: ESALQ, Depto. de Química, 1974. 56p.

SCHNUG, E.; FLECKENSTEIN, J.; HANEKLAUS, S. Coca cola $\circledast$ is it! The ubiquitous extractant for micronutrients in soil. Communications in Soil Science and Plant Analysis, v.27, p.1721-1730, 1996.

SHUMAN, L.M. Effect of organic matter on the distribution of manganese, copper, iron and zinc in soil fractions. Soil Science, v.146, p.192-198, 1988.

SINGH, B.R.; NORWAL, R.P. Plant availability of heavy metals in a sludge-treated soil: II. Metal extractability compared with plant metal uptake. Journal of Environmental Quaily, v.13, p.344-348, 1984.

SLOAN, J.J.; BASTA, N.T. Remediation of acid soils by using alkaline biosolids. Journal of Environmental Quality, v.24, p.1097-1103, 1995.

SMITH, S.R. Effect of soil $\mathrm{pH}$ on availability to crops of metals in sewage sludgetreated soils. I. Nickel, copper and zinc uptake and toxicity to ryegrass. Environmental Pollution, v.85, n.3, p. 321-327, 1994.

SOMMERS, L.E.; GIORDANO, P.M. Use of nitrogen from agricultural, industrial and municipal wastes. In: HAUCK, R.D. (Ed.). Nitrogen in crop production. Madison: ASA, 1984. p. 208-218. 
SPOSITO, G.; HOLTZCLAW, K.M.; LEVESQUE-MADORE, C.S. Cupric ion complexation by fulvic acid extracted from sewage sludge-soil mixtures. Soil Science Society of America Journal, v.50, p. 1406-1411, 1979.

SPOSITO, G.; LUND, L.J.; CHANG, A.C. Trace metal chemistry in arid-zone field soil amended with sewage sludge: I. Fractionation of $\mathrm{Ni}, \mathrm{Cu}, \mathrm{Zn}, \mathrm{Cd}$ and $\mathrm{PB}$ in solid phases. Soil Science Society of American Journal, v.46, p.260-264, 1982.

U. S. ENVIRONMENTAL PROTECTION AGENCY 1993. 40 CFR Parts 257, 403 and 503. Final rules: Standards for the use of sewage sludge. Fed. Reg. v.58, n.32, p.9248-9415.

WALLACE, A.; WALLACE, G.A. A possible flaw in EPAs 1993 new sludge rule due to heavy metals interactions. Communications in Soil Science and Plant Analysis, v.25, p.129-135, 1994. 
APÊNDICES 
Apêndice 1. Análise de variância para os dados de $\mathrm{pH}$ e condutividade elétrica no LV.

\begin{tabular}{ccccc}
\hline Causa de & \multicolumn{2}{c}{$\mathrm{pH}\left(\mathrm{CaCl}_{2} 0,01 \mathrm{~mol} \mathrm{~L}^{-1}\right)$} & \multicolumn{2}{c}{$\mathrm{CE}\left(\mathrm{mS} \mathrm{cm}^{-1}\right)$} \\
Variação & $\begin{array}{c}\text { Antes do } \\
\text { Plantio }\end{array}$ & $\begin{array}{c}\text { Após a } \\
\text { colheita }\end{array}$ & $\begin{array}{c}\text { Antes do } \\
\text { Plantio }\end{array}$ & $\begin{array}{c}\text { Após a } \\
\text { colheita }\end{array}$ \\
\hline Fonte & $* *$ & $* *$ & $* *$ & $* *$ \\
Relação Zn: Cu & $* *$ & $* *$ & $* *$ & $* *$ \\
Fonte X Rel. Zn:Cu & $* *$ & $* *$ & $* *$ & $* *$ \\
\hline dms 1\% (Fonte) & 0,22 & 0,16 & 0,07 & 0,04 \\
dms 1\% (Rel. Zn:Cu) & 0,45 & 0,33 & 0,15 & 0,09 \\
dms 1\% (Fonte X Rel. Zn:Cu) & 0,64 & 0,46 & 0,21 & 0,12 \\
\hline
\end{tabular}

** Teste $\mathrm{F}$ significativo a $99 \%$.

Apêndice 2. Análise de variância para os dados de pH e condutividade elétrica no LE.

\begin{tabular}{ccccc}
\hline Causa de & \multicolumn{2}{c}{$\mathrm{pH}\left(\mathrm{CaCl}_{2} 0,01 \mathrm{~mol} \mathrm{~L}^{-1}\right)$} & \multicolumn{2}{c}{$\mathrm{CE}\left(\mathrm{mS} \mathrm{cm}^{-1}\right)$} \\
Variação & Antes do & Após a & Antes do & Após a \\
& Plantio & colheita & Plantio & colheita \\
\hline Fonte & $* *$ & $* *$ & $* *$ & $* *$ \\
Relação Zn:Cu & $* *$ & $* *$ & $* *$ & $* *$ \\
Fonte X Rel. Zn:Cu & $* *$ & $* *$ & $* *$ & $* *$ \\
\hline dms 1\% (Fonte) & 0,19 & 0,17 & 0,08 & 0,02 \\
dms 1\% (Rel. Zn:Cu) & 0,39 & 0,36 & 0,16 & 0,04 \\
dms 1\% (Fonte X Rel. $\mathrm{Zn}: \mathrm{Cu})$ & 0,56 & 0,51 & 0,23 & 0,05 \\
\hline
\end{tabular}

** Teste $\mathrm{F}$ significativo a $99 \%$. 
Apêndice 3. Análise de variância para os resultados de massa seca produzida pela raiz, parte aérea e total das plantas de arroz cultivadas no LV.

\begin{tabular}{cccc} 
Causa de & Raiz & Parte Aérea & Total \\
Variação & $*$ & $* *$ & $* *$ \\
Fonte & $* *$ & $* *$ & $* *$ \\
Relação $\mathrm{Zn:Cu}$ & $* *$ & $* *$ & $1,14^{* *}$ \\
Fonte X Rel. Zn:Cu & $0,61^{*}$ & $0,72^{* *}$ & 2,37 \\
\hline dms 1** ou 5*\% (Fonte) & 1,27 & 1,50 & 3,35 \\
dms 1\% (Rel. Zn:Cu) & 1,79 & 2,12 & \\
\hline
\end{tabular}

** Teste $\mathrm{F}$ significativo a $99 \%$.

* Teste F significativo a $95 \%$

Apêndice 4. Análise de variância para os resultados de massa seca produzida pela raiz, parte aérea e total das plantas de arroz cultivadas no LE.

\begin{tabular}{cccc} 
Causa de & Raiz & Parte Aérea & Total \\
Variação & $* *$ & $* *$ & $* *$ \\
\hline Fonte & $* *$ & $* *$ & $* *$ \\
Relação Zn:Cu & $* *$ & $* *$ & $* *$ \\
Fonte X Rel. Zn:Cu & 0,33 & 1,18 & 1,35 \\
\hline dms 1\% (Fonte) & 0,68 & 2,46 & 2,86 \\
dms 1\% (Rel. Zn:Cu) & 0,96 & 3,48 & 3,97 \\
\hline
\end{tabular}

** Teste $\mathrm{F}$ significativo a $99 \%$. 
Apêndice 5. Análise de variância para os teores de $\mathrm{Zn}$ e $\mathrm{Cu}$ absorvidos pelas plantas de arroz no LV.

\begin{tabular}{ccc} 
Causa de & \multicolumn{2}{c}{ LV } \\
Variação & $\mathrm{Zn}\left(\mu \mathrm{g} \mathrm{g}^{-1}\right)$ & $\mathrm{Cu}\left(\mu \mathrm{g} \mathrm{g}^{-1}\right)$ \\
\hline Fonte & $* *$ & $*$ \\
Relação Zn:Cu & $* *$ & $* *$ \\
Fonte X Rel. Zn:Cu & $* *$ & $* *$ \\
\hline dms 1** ou 5*\% (Fonte) & $24,12^{* *}$ & 1,34 \\
dms 1\% (Rel. Zn:Cu) & 50,19 & 1,89 \\
\hline
\end{tabular}

** Teste F significativo a $99 \%$.

* Teste F significativo a $95 \%$.

Apêndice 6. Análise de variância para os teores de $\mathrm{Zn}$ e $\mathrm{Cu}$ absorvidos pelas plantas de arroz no LE.

\begin{tabular}{ccc}
\hline Causa de & \multicolumn{2}{c}{ LE } \\
Variação & $\mathrm{Zn}\left(\mu \mathrm{g} \mathrm{g}^{-1}\right)$ & $\mathrm{Cu}\left(\mu \mathrm{g} \mathrm{g}^{-1}\right)$ \\
\hline Fonte & $* *$ & $* *$ \\
Relação Zn:Cu & $* *$ & $* *$ \\
Fonte X Rel. Zn:Cu & $* *$ & $* *$ \\
\hline dms 1** ou 5*\% (Fonte) & $15,76^{* *}$ & $0,48^{* *}$ \\
dms 1\% (Rel. Zn:Cu) & 32,80 & 0,99 \\
dms 1\% (Fonte X Rel. Zn:Cu) & 46,39 & 1,40 \\
\hline
\end{tabular}

** Teste $\mathrm{F}$ significativo a $99 \%$.

* Teste F significativo a $95 \%$. 
Apêndice 7. Teores de zinco presentes no solo removidos por diversos extratores (médias de três repetições).

\begin{tabular}{|c|c|c|c|c|c|c|}
\hline \multirow[b]{2}{*}{ Solos ${ }^{(1)}$} & \multirow[b]{2}{*}{$\begin{array}{c}\text { Fonte de } \\
\mathrm{Zn} \mathrm{e} \mathrm{Cu}\end{array}$} & \multirow[b]{2}{*}{$\begin{array}{l}\text { Relação } \\
\mathrm{Zn}: \mathrm{Cu}\end{array}$} & \multicolumn{3}{|c|}{ Teores solúveis } & \multirow{2}{*}{$\begin{array}{c}\begin{array}{l}\text { Teores } \\
\text { Totais }\end{array} \\
\text { Água Régia }\end{array}$} \\
\hline & & & $\begin{array}{c}\mathrm{HCl} \\
0,1 \mathrm{~mol} \mathrm{~L}^{-1}\end{array}$ & MEHLICH-3 & DTPA & \\
\hline \multirow{12}{*}{ LV } & & & - & $\ldots(\mathrm{mg}$ & $\left.g^{-1}\right)$ & - \\
\hline & Testemunha & - & 2 & 2 & 1 & 24 \\
\hline & & $5: 1$ & 20 & 13 & 9 & 163 \\
\hline & Lodo & $7: 1$ & 67 & 53 & 28 & 260 \\
\hline & & $1: 1$ & 25 & 18 & 9 & 143 \\
\hline & & $4: 1$ & 32 & 33 & 27 & 174 \\
\hline & Testemunha & - & 2 & 2 & 1 & 25 \\
\hline & \multirow{4}{*}{ Sal } & $5: 1$ & 73 & 66 & 50 & 589 \\
\hline & & $7: 1$ & 205 & 241 & 137 & 15845 \\
\hline & & $1: 1$ & 71 & 78 & 48 & 445 \\
\hline & & $4: 1$ & 108 & 127 & 80 & 831 \\
\hline & C.V. $\%$ & & 6 & 4 & 3 & 4 \\
\hline
\end{tabular}

\begin{tabular}{|c|c|c|c|c|c|c|}
\hline \multirow{11}{*}{ LE } & Testemunha & - & 2 & 2 & 1 & 73 \\
\hline & & $5: 1$ & 15 & 13 & 9 & 171 \\
\hline & Lodo & $7: 1$ & 68 & 64 & 35 & 373 \\
\hline & & $1: 1$ & 24 & 19 & 9 & 161 \\
\hline & & $4: 1$ & 31 & 30 & 21 & 177 \\
\hline & Testemunha & - & 2 & 2 & 1 & 73 \\
\hline & \multirow{4}{*}{ Sal } & $5: 1$ & 70 & 62 & 35 & 641 \\
\hline & & $7: 1$ & 174 & 156 & 71 & 1931 \\
\hline & & $1: 1$ & 66 & 63 & 37 & 498 \\
\hline & & $4: 1$ & 106 & 86 & 65 & 990 \\
\hline & C.V. $\%$ & & 5 & 3 & 2 & 5 \\
\hline
\end{tabular}

${ }^{(1)} \mathrm{LV}$ refere-se a parte do experimento realizada com Latossolo Vermelho Amarelo e LE com Latossolo Vermelho Escuro 
Apêndice 8. Teores de cobre presentes no solo removidos por diversos extratores (médias de três repetições).

\begin{tabular}{|c|c|c|c|c|c|c|}
\hline \multirow[b]{2}{*}{ Solos ${ }^{(2)}$} & \multirow[b]{2}{*}{$\begin{array}{l}\text { Fonte de } \\
\mathrm{Zn} \mathrm{e} \mathrm{Cu}\end{array}$} & \multirow[b]{2}{*}{$\begin{array}{l}\text { Relação } \\
\mathrm{Zn}: \mathrm{Cu}\end{array}$} & \multicolumn{3}{|c|}{ Teores solúveis } & \multirow{2}{*}{$\begin{array}{l}\text { Teores Totais } \\
\text { Água Régia }\end{array}$} \\
\hline & & & $\begin{array}{c}\mathrm{HCl} \\
0,1 \mathrm{~mol} \mathrm{~L}^{-1}\end{array}$ & MEHLICH-3 & DTPA & \\
\hline \multirow{12}{*}{ LV } & & & - & $(m$ & $\left.\mathrm{kg}^{-1}\right) \cdots$ & \\
\hline & Testemunha & - & 0,6 & 1,1 & $0,5 \mathrm{a}$ & 12,0 \\
\hline & \multirow{4}{*}{ Lodo } & $5: 1$ & 3,4 & 3,4 & $2,4 \mathrm{~b}$ & 50,7 \\
\hline & & $7: 1$ & 3,5 & 4,5 & $2,7 \mathrm{~b}$ & 89,3 \\
\hline & & $1: 1$ & 21,8 & 45,1 & $30,7 \mathrm{c}$ & 129,3 \\
\hline & & $4: 1$ & 5,3 & 5,1 & $4,3 \mathrm{~b}$ & 90,0 \\
\hline & Testemunha & - & 0,6 & 1,1 & $0,5 \mathrm{~A}$ & 12,1 \\
\hline & \multirow{4}{*}{ Sal } & $5: 1$ & 8,1 & 15,8 & $8,6 \mathrm{~B}$ & 145,3 \\
\hline & & $7: 1$ & 17,1 & 27,0 & $16,7 \mathrm{C}$ & 284,0 \\
\hline & & $1: 1$ & 69,1 & 96,5 & $79,9 \mathrm{D}$ & 962,7 \\
\hline & & 4:1 & 16,8 & 27,4 & $17,8 \mathrm{C}$ & 325,3 \\
\hline & C.V. $\%$ & & 3,8 & 8,5 & 3,8 & 5,5 \\
\hline \multirow{11}{*}{ LE } & Testemunha & - & 2,3 & 3,3 & 1,9 & 34,7 \\
\hline & & $5: 1$ & 3,7 & 5,8 & 2,8 & 94,7 \\
\hline & Lodo & $7: 1$ & 4,3 & 8,1 & 4,0 & 120,7 \\
\hline & & $1: 1$ & 24,9 & 49,7 & 23,6 & 316,0 \\
\hline & & $4: 1$ & 5,4 & 6,6 & 4,3 & 136,7 \\
\hline & Testemunha & - & 2,4 & 3,3 & 1,9 & 34,7 \\
\hline & \multirow{4}{*}{ Sal } & $5: 1$ & 10,9 & 12,3 & 8,6 & 169,3 \\
\hline & & $7: 1$ & 19,2 & 20,6 & 13,2 & 428,0 \\
\hline & & $1: 1$ & 52,8 & 65,6 & 52,1 & 933,3 \\
\hline & & $4: 1$ & 14,6 & 22,2 & 12,9 & 629,3 \\
\hline & C.V. $\%$ & & 4,5 & 5,2 & 1,7 & 5,1 \\
\hline
\end{tabular}

${ }^{(1)}$ LV refere-se a parte do experimento realizada com Latossolo Vermelho Amarelo e LE com Latossolo Vermelho Escuro 
Apêndice 9. Análise de variância para os tores de de $\mathrm{Zn}$ e $\mathrm{Cu}$ removidos pelos extratores no LV.

\begin{tabular}{|c|c|c|c|c|c|}
\hline \multirow{3}{*}{ Elemento } & \multicolumn{4}{|c|}{$\mathrm{HCl} 0,01$} & \multirow{2}{*}{$\begin{array}{l}\text { Água } \\
\text { Régia }\end{array}$} \\
\hline & Causa de & $\mathrm{mol} \mathrm{L}^{-1}$ & Mehlich-3 & DTPA & \\
\hline & Variação & \multicolumn{4}{|c|}{$\mu_{g} g^{-1}$} \\
\hline \multirow{6}{*}{ ZINCO } & Fonte & ** & *** & *** & ** \\
\hline & Relação Zn:Cu & ** & $* *$ & $* *$ & $* *$ \\
\hline & Fonte $\mathrm{X}$ Rel. $\mathrm{Zn}: \mathrm{Cu}$ & $* *$ & ** & ** & ** \\
\hline & dms $1 \%$ (Fonte) & 3,99 & 2,72 & 1,33 & 16,58 \\
\hline & dms $1 \%($ Rel. $\mathrm{Zn}: \mathrm{Cu})$ & 8,29 & 5,67 & 2,76 & 34,50 \\
\hline & dms $1 \%$ (Fonte X Rel. $\mathrm{Zn}: \mathrm{Cu}$ ) & 11,73 & 8,01 & 3,91 & 48,79 \\
\hline \multirow{6}{*}{ COBRE } & Fonte & *** & ** & ** & $* *$ \\
\hline & Relação $\mathrm{Zn}: \mathrm{Cu}$ & ** & ** & ** & ** \\
\hline & Fonte X Rel. $\mathrm{Zn}: \mathrm{Cu}$ & $* *$ & $* *$ & ** & $* *$ \\
\hline & dms $1 \%$ (Fonte) & 0,58 & 2,01 & 0,65 & 12,09 \\
\hline & dms $1 \%(\operatorname{Rel} . \mathrm{Zn}: \mathrm{Cu})$ & 1,20 & 4,18 & 1,34 & 25,15 \\
\hline & dms $1 \%$ (Fonte X Rel. $\mathrm{Zn}: \mathrm{Cu}$ ) & 1,69 & 5,92 & 1,90 & 35,57 \\
\hline
\end{tabular}

** Teste $\mathrm{F}$ significativo a $99 \%$. 
Apêndice 10. Análise de variância para os tores de de $\mathrm{Zn}$ e $\mathrm{Cu}$ removidos pelos extratores no LE.

\begin{tabular}{|c|c|c|c|c|c|}
\hline \multirow{3}{*}{ Elemento } & \multicolumn{4}{|c|}{$\mathrm{HCl} 0,01$} & \multirow{2}{*}{$\begin{array}{l}\text { Água } \\
\text { Régia }\end{array}$} \\
\hline & Causa de & $\mathrm{mol} \mathrm{L}^{-1}$ & Mehlich-3 & DTPA & \\
\hline & Variação & \multicolumn{4}{|c|}{$\mu g^{-1}$} \\
\hline \multirow{6}{*}{ ZINCO } & Fonte & $* *$ & $* *$ & ** & ** \\
\hline & Relação $\mathrm{Zn:Cu}$ & $* *$ & $* *$ & $* *$ & $* *$ \\
\hline & Fonte X Rel. $\mathrm{Zn}: \mathrm{Cu}$ & $* *$ & $* *$ & $* *$ & $* *$ \\
\hline & dms $1 \%$ (Fonte) & 0,65 & 1,54 & 0,62 & 25,51 \\
\hline & dms 1\% (Rel. $\mathrm{Zn}: \mathrm{Cu})$ & 1,36 & 3,20 & 1,28 & 53,09 \\
\hline & dms $1 \%$ (Fonte X Rel. $\mathrm{Zn}: \mathrm{Cu}$ ) & 1,92 & 4,52 & 1,81 & 75,08 \\
\hline \multirow{6}{*}{ COBRE } & Fonte & $* *$ & $* *$ & $* *$ & $* *$ \\
\hline & Relação $\mathrm{Zn:Cu}$ & $* *$ & $* *$ & $* *$ & $* *$ \\
\hline & Fonte $\mathrm{X} \mathrm{Rel}: \mathrm{Zn}: \mathrm{Cu}$ & $* *$ & $* *$ & $* *$ & $* *$ \\
\hline & dms $1 \%$ (Fonte) & 2,60 & 1,07 & 0,22 & 15,22 \\
\hline & dms 1\% (Rel. $\mathrm{Zn}: \mathrm{Cu})$ & 5,42 & 2,23 & 0,46 & 31,67 \\
\hline & dms $1 \%$ (Fonte X Rel. $\mathrm{Zn}: \mathrm{Cu})$ & 7,66 & 3,15 & 0,65 & 44,79 \\
\hline
\end{tabular}

** Teste $\mathrm{F}$ significativo a $99 \%$. 